\title{
ABSTRACT
}

Title of thesis:

\section{CLIENT CONCEALMENT AND DISCLOSURE OF SECRETS IN OUTPATIENT PSYCHOTHERAPY}

Ellen Baumann, Master of Science, 2014

\author{
Thesis directed by: $\quad$ Professor Clara Hill \\ Department of Psychology
}

This study investigated client motivations for concealing versus disclosing secrets in therapy as well as how this negotiation process relates to therapeutic process and outcome. About half of the participants had both revealed a secret and were concealing a secret in therapy. Disclosed secrets were most likely to be related to relationships and were disclosed because the clients felt they could trust their therapists and because they thought they could benefit from sharing the secret. Concealed secrets were most likely to be sexual in nature and to be concealed due to shame or embarrassment. Clients initially experienced comparable levels of negative and positive emotions when they first disclosed their secret. However, over time, their feelings about the disclosure became more positive and less negative. Concealment was negatively related to the real relationship. 


\title{
CLIENT CONCEALMENT AND DISCLOSURE OF SECRETS IN OUTPATIENT PSYCHOTHERAPY
}

\author{
by \\ Ellen Christina Baumann \\ Thesis submitted to the faculty of the Graduate School of the \\ University of Maryland, College Park in partial fulfillment \\ of the requirements for the degree of \\ Master of Science \\ 2014
}

Advisory Committee:

Professor Clara Hill, Chair

Professor Charles Gelso

Professor Mary Ann Hoffman 
(C)Copyright by

Ellen Christina Baumann

2014 


\section{TABLE OF CONTENTS}

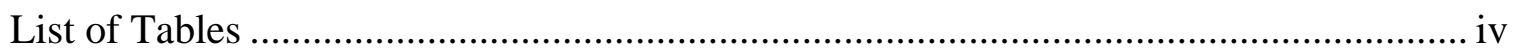

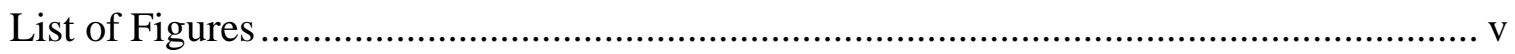

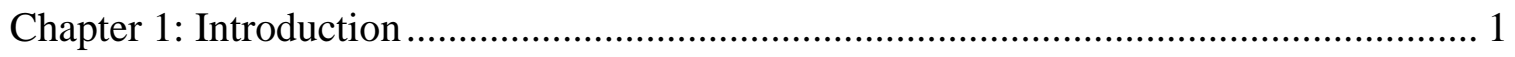

Chapter 2: Review of the Literature................................................................................ 7

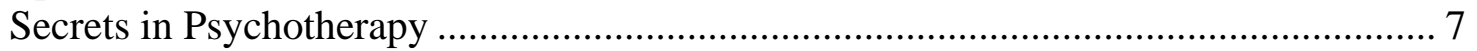

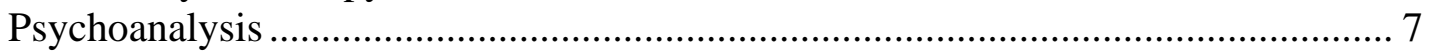

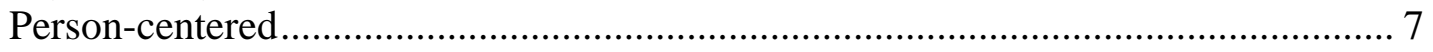

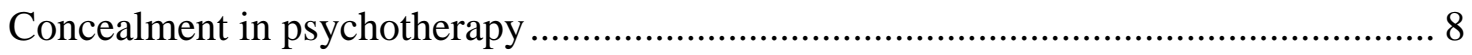

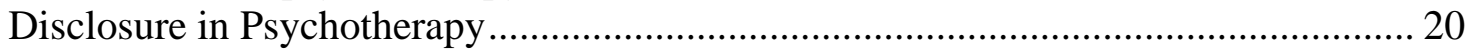

Concealment and Disclosure of Secrets Outside of Therapy.......................................... 32

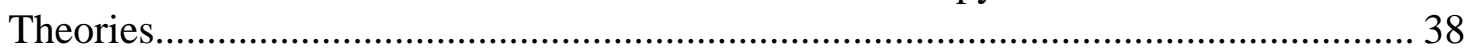

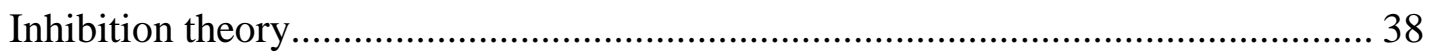

Preoccupation model........................................................................................ 39

Self-presentational perspective ............................................................................. 40

Self-monitoring theory ………………….......................................................... 42

Fever model of disclosure................................................................................... 42

Negative reinforcement............................................................................................. 43

Chapter 3: Statement of the Problem .................................................................................... 45

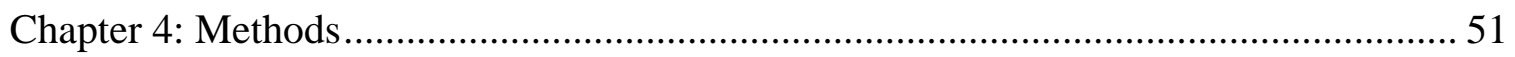

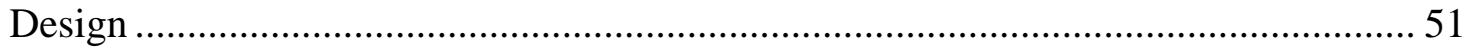

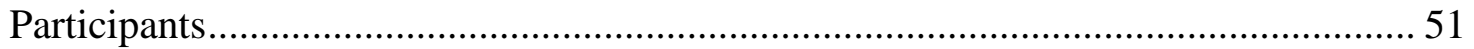

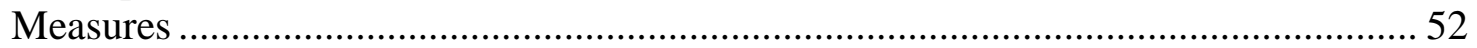

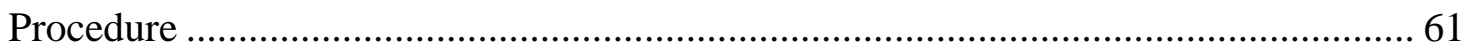

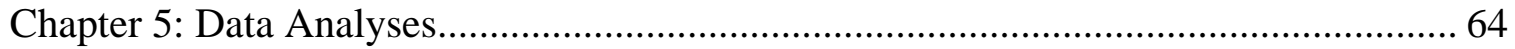

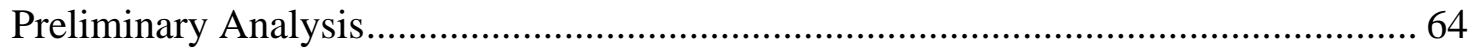

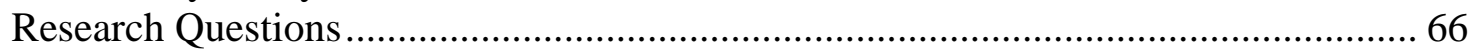

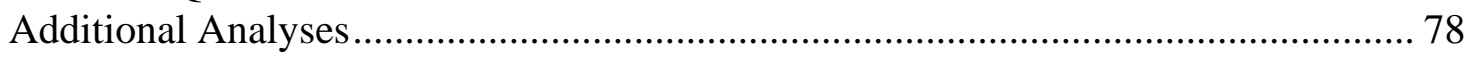

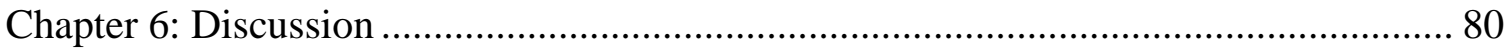

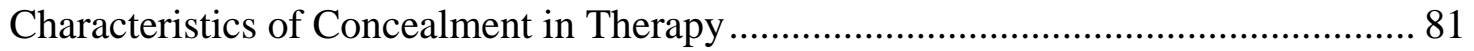

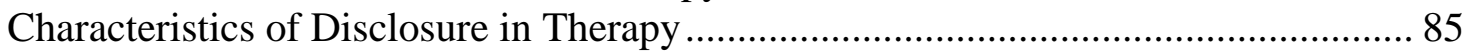

Comparison of Concealed Versus Disclosed Secrets ...................................................... 89

Concealment and Disclosure in Relation to Therapy Process and Outcome................. 91

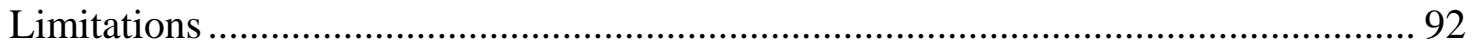

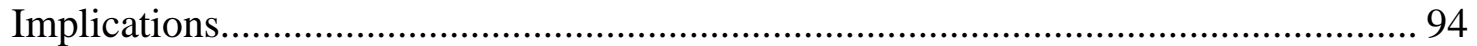

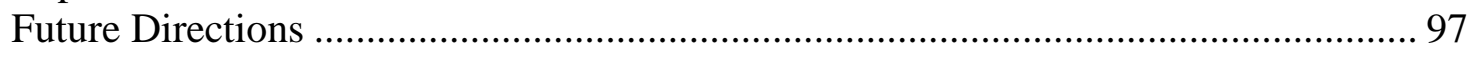


Appendix C: Client Outcome Measure............................................................................ 102

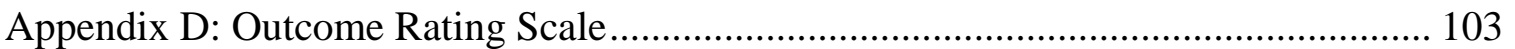

Appendix E: Disclosure and Concealment Questionnaire................................................ 104

Appendix F: Demographics Questionnaire.................................................................. 110

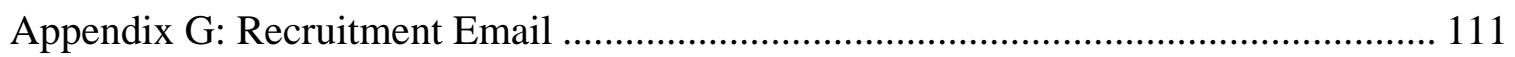

Appendix H: Recruitment Email for Graduate Student Clients........................................ 113

Appendix I: Snowballing Recruitment Email for Clients................................................. 114

Appendix J: Recruitment Notice for FYI Listserv........................................................ 115

Appendix K: Client Recruitment Flyer................................................................ 116

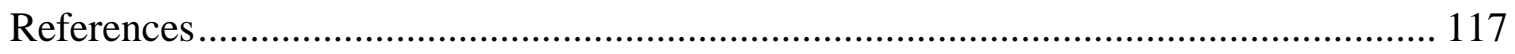


List of Tables

Table 1: Factor Loadings for Emotion Scale...................................... 58

Table 2: Means, Standard Deviations, Internal Consistency, and Correlations of all

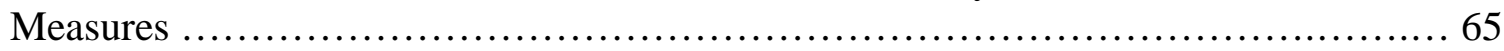

Table 3: Frequencies and Percentages of Disclosing Versus Concealing Secrets.......... 67

Table 4: Types of Secrets Concealed Versus Disclosed............................. 68

Table 5: Frequencies and Percentages of Reasons for Concealing Secrets............. 69

Table 6: Frequencies and Percentages of Reasons for Disclosing Secrets.............. 69

Table 7: Frequencies and Percentages of Imagined Gains Versus Actual Gains......... 71

Table 8: Frequencies and Percentages for Potential Influences of Disclosure........... 71

Table 9: Means and Standard Deviations of Level of Positive and Negative Emotions as

Compared to Norm Data....................................................... 74 


\section{List of Figures}

Figure 1: Negative and Positive Emotions Regarding Concealment, Feelings Immediately Following Disclosure, Feelings at Time of Survey Regarding Disclosure ....

Figure 2: Average Negative and Positive Emotions Regarding Concealment, Feelings Immediately Following Disclosure, and Feelings at Time of Survey Regarding Disclosure.... 


\section{Chapter 1: Introduction}

In our third session, a client told me that she had a tendency to lie to the important people in her life, mainly about small things, as a way of avoiding disappointing others and asserting control over her own life. Through the sharing of this secret and the mutual exploration that followed, I felt the client open up, and I experienced a connection with her for the first time. I cannot presume exactly what the experience was like for the client, but at the end of the session, she said, "That felt good. That was necessary. Yeah, I’ve been kind of hiding that from you, too. I shouldn't have hid that from you, my whole actual life, what's actually going on. And so I was like, 'I need to tell her about it. I just need to let it out,' so we both know... so you know about my life.”

However, the story does not end there. The client canceled the next two sessions and then went home for break. Though she promised to return the next semester, she did not return. While I cannot say for sure what prompted the client's cancellations, sharing her secret may have stirred up difficult and conflicting feelings. Perhaps her disclosure influenced her decision not to continue with therapy, though this is something I will never know for sure.

Client disclosure was at the core of Freud's psychoanalysis (1913/1958), an orientation that encouraged clients to free associate as a means of disclosing as much as possible in order to tap into the client's unconscious processes. Other theoretical orientations likewise view self-disclosure as a vital aspect of therapy (Farber, Berano, \& Capobianco, 2004), but research has shown that clients tend to keep some secrets from their therapists (Hill, Thompson, Cogar, \& Denman, 1993; Kelly, 1998). Yalom (1970) found that when clients in encounter groups wrote down their biggest secrets, three 
common themes emerged: They felt deeply inadequate, they felt alienated from others, and the secrets tended to be sexual in nature. Thus, there seem to be some commonalities in the client experience of concealment.

Studies focused on the effects of concealment have indicated that keeping thoughts, feelings, and experiences hidden is challenging and plays a role in the development of physical illness (Pennebaker, 1985; Uysal \& Lu, 2011). Studies have also found that self-concealment (one’s tendency to conceal distressing or negative personal information) is related to negative psychological effects, such as lower levels of well-being and life satisfaction (Larson \& Chastain, 1990; Uysal, Lin, \& Knee, 2010). However, whereas concealment has been studied extensively outside of psychotherapy, only a few studies have looked at secret keeping within the therapeutic relationship.

Findings from the studies that have looked at concealment in psychotherapy have been mixed. Some studies have indicated that client secret-keeping has a negative relationship with certain aspects of therapy, including client satisfaction and the working alliance (Farber et al., 2004; Kahn \& Hessling, 2001; Kelly \& Yuan, 2009). Others, however, indicate a benefit in concealing secrets from therapists (Kelly 1998, 2000; Regan \& Hill, 1992). In these studies, concealment has been defined in different ways, with some researchers looking only at the concealment of distressing information and others looking at all types of concealment (Kahn, Achter, \& Shambaugh, 2001). These differing definitions of the construct may have contributed to the inconsistent findings. Alternatively, these findings may speak to the complex relationships clients have with their secrets, that sometimes it may indeed feel better to conceal them than to disclose. 
In addition to focusing on concealment of secrets in therapy, researchers have focused on the disclosure of traumatic or distressing experiences. Experiments using writing techniques have shown that disclosing painful feelings or experiences is related to positive health outcomes, including increased immune functioning and decreased utilization of health services (Booth, Petrie \& Pennebaker, 1997; Pennebaker, 1997; Pennbaker \& Beall, 1986; Pennebaker, Kiecolt-Glaser, \& Glaser, 1988; Rosenberg et al., 2002). In addition, studies focusing on disclosure in psychotherapy have shown positive effects (Farber et al., 2004; Farber, Berano, \& Capobianco, 2006; Kahn et al., 2001, Kelly, Klusas, von Weiss, \& Kenny, 2001). For instance, Farber et al. (2004) found that the process of disclosing difficult information in therapy brought up initial feelings of shame, but ultimately led to feelings of relief and authenticity. Most of these clients believed that self-disclosure was always in their best interest, despite the initial negative feelings. Similar to concealment, disclosure in therapy has been defined in multiple ways, with some researchers focusing on negative or distressing disclosures and others looking at all types of disclosures.

Since concealment and self-disclosure can be considered to be conceptually different (and not on opposite ends of a continuum), researchers have typically focused on either concealment or disclosure (Kahn \& Hessling, 2001). However, with any secret, there is a choice whether or not to conceal or disclose it, and clients may feel ambivalent about which to choose. Clients may conceal some secrets and disclose others. Indeed, Farber et al. (2004) found that despite the apparent benefits of disclosure, client fears make it difficult to disclose deeply felt personal issues in therapy, and even clients who agreed that it was always better to disclose in therapy often kept some secrets. Thus, it 
seems that clients feel pulled both to disclose and to conceal, and that there is an inner negotiation process in determining whether or not to share a secret. Although concealment of secrets has been studied in the past, most disclosure research has focused on disclosures related to general topics and distressing experiences (Farber \& Hall, 2002; Kahn \& Hessling, 2001). One data set included information on disclosures of secrets combined with disclosures of deeply felt personal issues (Farber et al., 2004, 2006). However, it is unclear the extent to which clients disclose secrets in therapy and whether these secrets are similar to the types of secrets that are concealed. It makes sense to look at both those secrets that are concealed as well as those clients choose to disclose to get a more complete picture of what is happening with regards to secrets.

Certain clients may come to therapy specifically to disclose certain secrets that they feel they cannot share with others, and they may disclose these secrets within their first few sessions with little ambivalence. These clients identify their need to share these secrets with someone and identify therapy as a safe environment to do so. For others, however, there seems to be a process of negotiation in the disclosure of secrets in psychotherapy. Initially, these clients may conceal their secrets, which is consistent with how they monitor their image outside of therapy by refraining from sharing negative information with others (Kelly, 2000). Although clients may desire to share their secrets and be truly known, they often do not initially disclose because of fear of disapproval or rejection from their therapists. Even clients who initiate therapy with the aim of sharing something specific may encounter difficulty actually disclosing. It is likely that sharing a secret or personal information with another in the past has backfired, conditioning clients to expect judgment or rejection in response to sharing secrets. Along with the fear of 
rejection from others comes self-stigma, the feeling that if clients have secrets they cannot share, they must be bad or shameful (Seibold, 2008).

As therapy progresses, clients negotiate whether to disclose their secrets or to keep them concealed. They know that therapy is supposed to be a safe place to disclose information, an environment different from most others. They likely feel pulled to do both, which is evident through client feelings of ambivalence leading up to the disclosure (Farber et al., 2006). Perhaps clients start by sharing a small secret as a means of testing how the therapist will respond and whether it is safe to disclose (Yalom, 1970). If the small secret is disclosed and the therapist is accepting, clients hopefully experience relief and self-acceptance (Farber et al. 2006). This feeling in turn facilitates additional disclosures and an improved self-concept (Farber et al, 2006). Thus, violating the expectation of judgment in response to disclosing secrets provides a corrective experience for clients. The key to this model is the acceptance of the clients by their therapists, which mitigates the shame felt about their secrets.

In this study, I define secrets (based on Hill et al., 1993; Kelly, 1998; Larson \& Chastain, 1990) as major life experiences, personal facts, thoughts or feelings that occur outside of the therapeutic relationship that one purposefully keeps from important people in his/her life because these secrets are perceived as negative, embarrassing, or distressing. The content of the secrets may range from mildly uncomfortable to highly troubling. Secrets are maintained through the avoidance of certain topics of conversation, the withholding of details when discussing topics, and/or the alteration or fabrication of personal information. Secrets are disclosed in therapy when this often-concealed material is revealed to the therapist, either through the client bringing up the topic him/herself or 
through exploration of topics brought up by the therapist.

In this study, I sought to gain a more in depth view of secrets, not just those concealed, but those disclosed in therapy as well. For this study, I chose to focus specifically on a subcategory of disclosure I call disclosure of secrets because this focus may allow for a more direct comparison to concealed secrets. I aim to investigate client motivations for concealing versus disclosing secrets in order to better understand how clients negotiate the sharing process in therapy. I also hope to learn more about how this negotiation process relates to therapeutic process and outcome. These results may tell a different story than looking at concealment or disclosure of secrets in isolation from one another. 


\section{Chapter 2: Review of the Literature}

The first section of this chapter outlines how client secrets have historically been viewed in psychotherapy. The next section will provide a detailed review of the research most relevant to the proposed study, namely, studies focused on concealing versus disclosing client secrets in psychotherapy. I will then provide an overview of empirical studies that have focused on concealment and disclosure of secrets in non-counseling settings. This chapter will conclude with selected theories that may help explain client motivations for disclosure and concealment and for the effects of secrets on their holders.

\section{Secrets in Psychotherapy \\ Psychoanalysis}

Historically, concealment in psychotherapy has been looked upon unfavorably. Freud's (1913) fundamental rule encouraged clients to "be absolutely honest and never leave anything out because for some reason or other it is unpleasant to tell it” (p. 135). Through disclosing everything, the client opens up a door to his/her unconscious and allows repressed content to emerge. This was considered key to the healing process. However, Freud (1913) also acknowledged that being completely honest is difficult, and he urged analysts to recall the difficulties from their own analyses when their analysands failed to be fully forthcoming. While psychoanalysis has progressed and changed through the years, disclosure remains “at the heart of therapy” (Stiles, 1995, p. 71).

\section{Person-centered}

Carl Rogers (1957) focused on the role of the therapist in facilitating an open and honest relationship with the client. In his “necessary and sufficient conditions,” he outlined the need for the therapist to have "unconditional positive regard" and empathy 
and to be able to communicate these effectively to the client (pp. 95-96). He encouraged the therapist to self-disclose in order to facilitate a genuine relationship with the client. Client self-disclosure was not listed as necessary for therapeutic change. However, by creating an empathic environment, the therapist likely allows the client to feel safe in disclosing personal information.

\section{Concealment in psychotherapy}

A few studies have looked specifically at secret keeping and related covert processes in psychotherapy. Here, I review the studies that examined concealment (secrets), focusing on the results relevant to client concealment in counseling.

Regan and Hill (1992) investigated the things that clients and therapists leave unsaid in therapy. Their aim was to compare what clients and therapists do not reveal in sessions and to investigate how these covert processes relate to session satisfaction and symptom change. They also sought to assess how often clients and counselors guessed what the other left unsaid and how these conjectures related to process and outcome variables. Finally, they wondered if they could classify covert processes into specific categories. Twenty-four graduate student therapists and volunteer client dyads each completed 6 sessions of psychotherapy (one dyad only completed 4 sessions). In a screening interview, clients identified a number of target complaints; issues with assertiveness had to be one of these in order for the client to qualify for the study. Prior to starting their 6 sessions of therapy, counselors and clients rated how much each target issue was currently affecting the client. After each session, therapists and clients reported the thoughts and feelings they had kept hidden and tried to guess what the other had left unsaid. They also assessed the quality and comfort of each session. Shortly after ending 
therapy, clients and therapists re-rated the target complaints, and clients rated their satisfaction with the therapy. Four judges classified each unspoken thing into one of three content categories: behaviors/cognitions, emotions, or clinical conjectures. They also rated the valence of the unspoken thoughts and feelings on a 5-point Likert scale ranging from 1 = very negative to 5 = very positive.

Clients left 0-6 things unsaid per session (Regan \& Hill, 1992). The quantity and valence of things left unsaid by both clients and therapists was unrelated to session number, indicating no change over time. Additionally, the content of what was left unsaid by clients tended to be slightly negative $(M=2.42, S D=.42$ on a 5 -point scale where $5=$ positive). This finding is in line with previous studies that have shown that clients are more likely to hide negative reactions than positive ones (Hill, Thompson, \& Corbett, 1992; Thompson \& Hill, 1991). While overall number of things left unsaid was unrelated to session process and outcome, there was a relationship when the researchers looked at the different content categories. Specifically, the number of unsaid things related to behaviors and cognitions was negatively related to client-rated session depth ( $r$ $=-0.42, p<.05)$, and satisfaction $(r=-0.54, p<.01)$. The number of unsaid things related to emotions was positively related to client-rated session depth $(r=43, p<.05)$, satisfaction $(r=.54, p<.01)$, and symptom change $(r=.43, p<.05)$. Thus, hiding behavioral and cognitive material was related to detrimental outcomes, while hiding emotions was related to positive outcomes. The researchers suggested that revealing emotions may feel dangerous and suggested that clients might have been adhering to social norms that discourage revealing strong feelings. They also theorized that it could be that when more emotional content was withheld, the client was exploring more 
emotions; conversely, perhaps when behaviors and thoughts were withheld, the sessions were lacking in emotional content. Thus, they suggested that what was disclosed in therapy may have mattered more than what was withheld.

Therapists were successful in guessing what clients left unsaid $17 \%$ of the time $(S D=.19)$. Therapist match rate was negatively correlated with therapist ratings of session smoothness $(r=-0.42, p<.05)$ and client ratings of treatment satisfaction $(r=$ $0.40, p<.05$ ), indicating that the more therapists could guess what clients left unsaid, the less smooth therapists perceived the sessions and the less satisfied clients were with the course of therapy. This finding challenges the notion that therapists should know everything about their clients, and the authors suggested that it might not be beneficial for therapists to know what clients conceal. This finding is also in line with another study that showed that therapist matching on negative client reactions led to less helpful subsequent interventions (Hill et al., 1992). The researchers theorized that since clients tend to leave negative reactions hidden, identifying these hidden reactions may have caused therapist trainees to get nervous and question their skills, leading to client behavior change that was perceived more negatively. Alternatively, perhaps certain clients hid their reactions poorly, and these overt reactions were easier to guess and contributed to rougher sessions and lower satisfaction.

The researchers acknowledged a couple of limitations. First, given that the volunteer clients all struggled with assertiveness, these clients may have had difficulty being assertive enough to share unsaid reactions. Perhaps clients with different presenting issues would report different results. The study also used therapist trainees, who may have been less adept at handling negative client reactions. Perhaps more 
experienced therapists would be able to guess clients' covert reactions and better channel that knowledge into helpful interventions. However, the authors noted that the findings in this study are similar to those in another study, which used both trainees and experienced therapists (Thompson \& Hill, 1991), indicating that perhaps using counselors in training did not drastically impact results (Regan \& Hill, 1992). Additionally, asking about undisclosed thoughts and feelings may have made clients more aware of these unsaid things, prompting them to modify their disclosure patterns in subsequent sessions. An additional limitation not mentioned by the authors is that there was no follow-up as to whether or not covert reactions were discussed in later sessions. If unsaid thoughts and feelings were addressed in later sessions, this could potentially have an impact on process and outcome. Finally, the study used volunteer clients, and volunteers who were deemed too symptomatic were referred elsewhere instead of taking part in the study, so the findings might not generalize to clients in psychotherapy.

Hill et al. (1993) identified three different kinds of covert processes exhibited by clients. The first is reactions, which are the "thoughts and feelings clients have in response to specific therapist interventions” (p. 278). The second is things left unsaid, which are the unshared responses clients have in a session that are unrelated to a specific therapist intervention. The third is secrets, which are the "major life experiences, facts, or feelings that clients do not tell their therapists” (Hill et al., 1993, p. 278). One important differentiation between processes is that reactions and things left unsaid arise in response to something within the session (either an intervention or something else that comes up) and exist only within the session. Secrets, on the other hand, are typically based on events, thoughts, or feelings that exist outside of the session (Hill at el., 1993). 
Thus, while hidden reactions and things left unsaid may be fleeting responses, secrets may be held over a long period of time and thus have a different effect on the secret holder.

Hill et al. (1993) aimed to investigate the role of these covert processes in longterm therapy, including the rate at which clients hide things from their therapists, the characteristics of things kept hidden, the reasons clients hide things from their therapists, how often therapists can tell what clients are hiding, and how therapist knowledge of what a client is hiding relates to session depth. Specifically pertaining to secrets, they aimed to investigate how many clients keep secrets from their therapists, how keeping a secret in therapy relates to session satisfaction, and if there are common types of secrets.

Twenty-three therapists and 26 clients together watched a videotape of a single session from their ongoing therapy. Therapists came from a wide range of orientations, and treatment was long term, with clients having an average of 86.23 sessions ( $\mathrm{SD}=$ 85.87) with their therapists. The videotaped session came from the middle of therapy treatment. After each intervention, they rated the helpfulness of the intervention, the client's hidden reactions, and the therapist's intentions. Both clients and therapists also rated the depth of the session. Additionally, clients rated their satisfaction with the session and specified what they left unsaid in the session, as well as their reasons for leaving those things unsaid. In terms of assessing secrets, clients were asked two openended questions: "What secrets do you have that you have not told your therapist?” and “Why have you not told your therapist?” Therapists were asked to make conjectures regarding what secrets their clients had kept hidden from them. 
Forty-six percent of clients $(N=12)$ indicated that they were keeping at least one secret from their therapists, with 9 listing one secret and 3 listing two secrets. Of these, $54 \%$ of clients kept secrets related to sex, $14 \%$ kept secrets related to failure, $14 \%$ kept secrets related to mental health, and 18\% kept "other" secrets. Three judges classified the reasons for secret keeping into 4 categories: shame or embarrassment $(n=8)$, not being able to handle the disclosure $(n=3)$, believing the therapist could not handle the disclosure $(n=2)$, and no reason $(n=3)$. Hill et al. found that secrets were not related to number of sessions, therapist ratings of session quality or client ratings of session satisfaction. Although not significant, a negative correlation between client-rated session quality and keeping a secret was found that approached significance.

Additionally, 17 clients (65\%) left one or more things unsaid in therapy, and most of these things were at least somewhat negative in valence (Hill et al., 1993). Twentyseven percent of therapists were able to correctly guess whether or not their client left something unsaid in the session and if they did leave something unsaid, roughly what it was. However, unlike Regan and Hill (1992), there was no relationship between session process or outcome variables and therapist ability to match client things left unsaid. Also, clients were more likely to withhold reactions that were negative or that were regarding the therapeutic work than they were when they were feeling supported or challenged. That clients withheld more than just negative reactions fits with Rennie's (1994) finding that clients experience deference towards the therapist and may withhold different types of reactions depending on the situation. When therapists were able to perceive that clients were hiding reactions regarding the therapeutic work being done, therapists rated the helpfulness of their interventions higher. This finding is in line with 
an earlier study (Thompson \& Hill, 1991) who found that therapist match on reactions associated with therapeutic work was related to an increase in helpfulness ratings of subsequent interventions.

Limitations of this study are that it used only a single session from the entire course of therapy for each dyad. While the researchers used sessions from the middle of treatment instead of beginning or termination sessions, it is impossible to tell if these selected sessions are representative of the therapy treatment. Additionally, although 300 therapists were invited to participate in the study, only 23 therapists did so. Thus, there may be something unique about these therapists who chose to take part in the study, and they may not accurately represent therapists in general. Additionally, these therapists may have asked clients to participate with whom therapy was going well. Clients themselves also had the opportunity to self-select, and so perhaps clients who chose to participate were confident in their relationship with their therapists and also may not be representative of clients in long-term therapy.

Kelly (1998) investigated the relationship between keeping a relevant secret in therapy and changes in symptomatology. She specifically targeted secrets relevant to therapy because non-relevant secrets would not be expected to have an impact on outcome. Each of 10 therapists working with outpatients at a hospital recruited 1 to 10 current clients to participate in the study, for a total of 42 clients. The number of sessions each client had prior to participating in the study ranged from 3 to 30 sessions $(M=$ $11.20, S D=8.10)$. Thirty-four of the 42 participants had already completed the Brief Symptoms Inventory (BSI; Derogatis, 1993), which assesses current severity of 53 symptoms. Upon agreeing to the study, clients completed the BSI to assess current 
symptomatology, the Self-Concealment Scale (SCS; Larson \& Chastain, 1990), which measures one's tendency to be secretive, and the Marlowe-Crowne Social Desirability Scale (MCSDS; Crowne \& Marlowe, 1940), which was included so that the researcher could control for social desirability in the analysis (Kelly, 1998). The participants also answered open-ended questions regarding their presenting issues, what relevant secrets they were keeping from their therapists, their reasons for keeping the secrets, and what they thought might be gained if they did share their secrets with their therapists.

Seventeen of the clients (40\%) indicated that they were keeping at least one relevant secret from their therapist. Three judges reviewed the types of secrets listed and created seven different categories of secrets. A second set of three judges classified the secrets into one of the seven categories: secret desire or secret relationship problems ( $\mathrm{n}=$ 7), sexual secrets $(n=4)$, health-related secrets $(n=2)$, substance abuse $(n=2)$, lying or delinquency $(n=1)$, and not specified $(n=1)(K e l l y, 1998)$. Three different judges classified the reasons given into one of seven categories: fear of expressing feelings ( $\mathrm{n}=$ 5), shame or embarrassment ( $n=3)$, fear of showing how little progress had been made in therapy $(\mathrm{n}=3)$, lack of time $(\mathrm{n}=3)$, total secrecy $(\mathrm{n}=2)$, loyalty to another individual ( $\mathrm{n}$ $=1)$, and not specified $(n=1)$. Three different judges classified the gains from revealing secrets into five categories: more insight or feedback $(n=10)$, catharsis or relief $(n=5)$, to fix the problem $(\mathrm{n}=3)$, to provide relevant information $(\mathrm{n}=3)$, and not specified $(\mathrm{n}=$ 3).

Both self-concealment and social desirability were related to higher symptomatology. However, after controlling for self-concealment, social desirability, and initial symptomatology, Kelly (1998) found that keeping a relevant secret was 
actually related to lower symptomatology. There was no relationship between number of sessions and secret keeping.

The results of this study are in line with previous findings that self-concealment, as a stable trait, is associated with negative health consequences (Kelly \& Achter, 1995; Larson \& Chastain; Uysal \& Lu, 2011). However, the findings also suggest that keeping a secret from one's therapist is not damaging in and of itself. These findings call into question whether secret keeping in therapy is in fact detrimental, which challenges the long held assumption that sharing everything in therapy is positive (Farber et al., 2004).

Kelly (1998) noted that a limitation of the study is that clients were not randomly selected. Therapists selected the clients they asked to participate. Additionally, clients had the choice as to whether or not to participate, so clients with damaging secrets may have refrained from participating. Additionally, there are a great number of variables that may impact treatment outcome, so perhaps keeping one or two secrets does not impact outcome very much. With a correlational design, it is impossible to control for other influencing factors. For instance, the study only looked at what secrets were withheld, so perhaps clients who kept secrets had more to work on in therapy and so they received benefits despite their concealment. Finally, secret keeping was only found to relate to symptom reduction after controlling for self-concealment. However, if one’s tendency to keep secrets is partialed out, one must question what the remaining construct (keeping a secret without being a secretive person) really is and if it has relevance in the real world (see also Hill, Gelso, \& Mohr, 2000).

Kelly and Yuan (2009) attempted to replicate Kelly’s (1998) finding that keeping a relevant secret was related to lower symptomatology in clients. They also aimed to 
explore the association between secret keeping and the working alliance. Twenty-two therapists working at three hospital sites participated in the study, and each enlisted one to eight current clients to participate, for a total of 83 clients. The number of sessions each client had prior to participating in the study ranged from 2 to $52(M=15.68, S D=$ 15.16), with no clients participating during a termination session. All clients had already completed the Basis-32 (Eisen, Grob, \& Klein, 1986), a measure of symptomatology, upon intake into the hospital. Upon agreeing to participate, each client also completed measures of symptomatology, working alliance, and social desirability. Clients also filled out a checklist of presenting problems, a checklist of the types of relevant secrets they were keeping from their therapist, and a checklist of reasons they were keeping these secrets; each of these checklists was created based on Kelly’s (1998) findings. Therapists assessed the working alliance and answered questions regarding whether or not they believed their clients were keeping a relevant secret and to what extent their clients’ presenting problems had decreased as a result of treatment.

Twenty-three clients (28\%) reported keeping a relevant secret (Kelly \& Yuan, 2009). The majority specified that they were keeping a secret related to sex/desire/relationships $(n=12)$ or a secret about a failure $(n=6)$. Other types of secrets were lying/cheating $(n=3)$, drugs $(n=1)$, and “other” $(n=8)$. The majority of clients specified keeping their secret due to shame $(n=14)$ or fear of sharing feelings $(n=11)$. Others reported that they would not tell anyone $(n=9)$, that revealing it would show how little progress had been made in therapy $(n=6)$, that they were not motivated to tell the therapist $(n=3)$, that they were being loyal to someone else $(n=1)$, and “other” $(n=5)$ 
(Kelly \& Yuan, 2009). There was no relationship between secret keeping and gender, nor was there a relationship between number of sessions and secret keeping.

Client ratings of the working alliance was negatively associated with keeping a relevant secret $(r=-.34, p=.002)$, with an effect size of $d=-.80$, indicating a large effect. Although therapists could not tell which clients were keeping secrets, therapist ratings of the working alliance were similarly negatively related to client report of secret keeping $(r=-.22, p=.05)$, with an effect size of $d=-.50$, indicating a medium effect. Controlling for initial symptomatology, Kelly and Yuan found that client-rated working alliance was positively related to changes in symptomatology (partial $r=.20, p=.03$ ), but therapist-rated working alliance and secret keeping were not associated with changes in symptomatology. Thus, secret keeping was negatively related to working alliance, but not significantly related to symptom change (Kelly \& Yuan, 2009). These findings challenge Kelly’s (1998) finding that keeping a secret was positively related to changes in symptomatology.

One important difference that might explain the discrepant results is that Kelly (1998) controlled for self-concealment, whereas Kelly and Yuan did not. One limitation of the study is that therapists selected the clients to participate in the study and therapists might have selected clients with whom their alliances were stronger. Furthermore, clients also self-selected by agreeing or not agreeing to the study. In this case, perhaps the clients who had a weaker working alliance or who were keeping a relevant secret shied away from the study. Additionally, using a checklist seemed to limit the findings. Eight of the 23 clients who reported keeping secrets selected “other” on the checklist regarding the content of secrets, and five of the 23 answered "other" as the reason why they kept 
their secret. Perhaps having open-ended questions would be better so as not to limit the choices of the participants. Finally, the operationalization of what a secret is may not have been done accurately because a definition of the construct was not provided to participants. With 83 clients, it is possible that the clients interpreted the question about keeping a relevant secret many different ways, as there was no standardized way of interpreting the construct.

Summary. The results of these studies suggest that 28 to $46 \%$ of clients conceal things from their therapists (Hill et al., 1993; Kelly, 1998; Kelly \& Yuan, 2009). These withheld things tend to be negative in valence. Keeping secrets is not associated with length of time in therapy, meaning that clients are not more likely to reveal their secrets in therapy the more sessions they have.

There was disagreement in the literature about whether therapist ability to guess what clients are hiding is related to session outcome. One study that focused on brief therapy and used inexperienced therapists showed a negative relationship between therapist match rate and session outcome, while another study that focused on long-term therapy and used experienced therapists did not show a negative relationship (Hill et al., 1993; Reagan \& Hill, 1992). This may indicate that experienced therapists are better able to smoothly handle hidden reactions and that having an established relationship and ample time to repair any ruptures that may arise may help therapists feel more comfortable and confident handling a secretive client.

Clients primarily kept secrets related to sex and failure, and they did so mainly because they were too ashamed or embarrassed to tell their therapists. This finding is in line with research done on secrets outside of therapy, which has indicated that shame and 
fear of rejection are main reasons that individuals do not share secrets (Derlega, Winstead, Greene, Serovich, \& Elwood, 2002; Finkenaur \& Rimé, 1998; Seibold, 2008; Vrij, Nunkoosing, Paterson, Oosterwegel, \& Soukara, 2002).

The relationship between secret keeping and session process and outcome variables is still unclear. One study (Kelly, 1998) found secret keeping was related to lower symptomatology, but this finding was only found after controlling for selfconcealment. Before partialing out self-concealment, keeping a secret was actually positively related to symptomatology. Additionally, two other studies (Hill et al., 1993;

Kelly \& Yuan, 2009) found no association between secret keeping and symptomatology, session depth, or client satisfaction; however, these studies did not partial out selfconcealment. Finally, one study (Kelly \& Yuan, 2009) found a negative association between secret keeping and the working alliance.

\section{Disclosure in Psychotherapy}

While some studies have focused on concealment of secrets in therapy, others have looked at the process of disclosing secrets and other personal information in therapy.

Farber and Hall (2002) sought to explore how much clients disclose to their therapists on a variety of topics. They also aimed to investigate the relationship between client disclosure and gender, shame-proneness, guilt-proneness and the therapeutic relationship. One hundred forty-seven psychotherapy clients participated in the study. They tended to be in long-term therapy ( $M=38.7$ months, $S D=32$ months). Additionally, $41 \%$ of the participants were mental health professionals. Clients completed the Disclosure-to-Therapist Inventory-Revised (DTI-R; Farber \& Hall, 1992), 
which assessed the level of disclosure on a nine different topics that ranged from moderately to highly personal (existential concerns, sexuality, narcissism, negative affect, procreation, intimacy, transference, money, and body issues.) Disclosure for each topic was assessed on a continuum, ranging from " $1=$ not at all” to " $5=$ discussed thoroughly." Clients also had the option of selecting "not applicable” if the topic did not apply to them. Clients also completed measures to assess their proneness to shame and guilt, as well as the therapeutic working alliance.

Overall, client disclosure fell in the midpoint range $(M=3.20, S D=.73)$, indicating a moderate level of disclosure (Farber \& Hall, 2002). Clients were least likely to thoroughly discuss issues regarding sexuality and procreation and most likely to thoroughly discuss negative feelings and intimacy issues. The only difference found between disclosures of men and women is that women scored higher in their discussion of issues related to procreation. However, there was no difference in overall levels of disclosure. Proneness to shame and guilt were not related to disclosure level. Working alliance and the length of time in therapy emerged as the two factors that most highly predicted total level of disclosure. Working alliance was also positively related to the level of disclosure on three specific topics: existential concerns, negative affect, and intimacy.

One limitation of the study is that the measure may not have adequately assessed all topics that can be discussed in therapy. For instance, as noted by the authors, issues related to violence were dropped from the initial factor analysis due to not enough participants endorsing those items (Farber \& Hall, 2002). However, items that are difficult to endorse or that do not reflect the common experience of many clients may be 
among those topics that are most difficult to talk about in therapy. Therefore, it may be important to have a way of assessing for those themes. Additionally, most topics included both positive and negative subjects. Since valence of items was not assessed, it is unclear the extent to which clients shared distressing information. Perhaps distresslevel of topics disclosed would be related to shame-proneness versus all disclosure, since some disclosure (i.e. disclosure of positive topics) may not elicit shame in a client.

Farber et al. (2004) used a multimethod approach to study the client process of determining what to conceal versus disclose in therapy. Semi-structured interviews were conducted with 21 psychotherapy clients who were currently in therapy. Most were engaged in psychodynamic psychotherapy (53\%), and the average time of therapy was 22.5 months ( $S D=14.7$; range 15-58 months). The interview consisted of 10 open-ended questions regarding the clients' experiences of disclosing and withholding information in therapy (e.g. “Can you describe how you’re feeling when you are disclosing something very personal or deeply felt?”) as well as 10 Likert-type scale questions regarding emotions felt immediately after disclosing in therapy. Following the interviews, a fourperson rating team developed common themes and categories for the responses. The responses were then categorized using the coding system.

Client reports showed mixed feelings and behaviors. Many clients reported that they felt afraid of their therapist's response, leading to feelings of anxiety before and during a disclosure and vulnerability after it (Farber et al., 2004). However, they also reported typically receiving an affirming response from the therapist when they did actually disclose and feeling proud, authentic, and relieved following the disclosure. Thus, clients' fears typically did not come to pass when disclosing, and their negative 
feelings gave rise to positive feelings that were statistically higher than their negative emotions $(t=1.59, p<.001)$. Furthermore, most of the clients believed that keeping secrets in therapy inhibits the therapeutic work being done and that, despite the uncomfortable feelings involved, it is always better to disclose. Almost all of the clients said that they did not regret their disclosures in therapy. However, in spite of this attitude, most clients did admit that there was at least one important issue that they had not yet brought up in therapy. Thus, clients seemed to see value in sharing secrets with their therapists, yet still had difficulty with disclosures, even when they had successfully disclosed in the past. While clients also affirmed that it is sometimes acceptable to keep things from one's therapist, most of them also wished that their therapists would sometimes actively inquire about their secrets.

Using the same data set, Farber et al. (2006) sought to identify common themes in how a disclosure unfolds. They found that clients in therapy typically have a positive attitude regarding self-disclosure. They usually feel ambivalent before the disclosure, with both a desire to disclose and a fear of their own or their therapist's reaction to the disclosure. During the disclosure, clients feel vulnerable, with some clients experiencing shame or embarrassment. Then, positive emotions follow the disclosure. Clients typically want therapist approval and report that they usually get it following a disclosure. Finally, they found that positive disclosure experiences in therapy beget future disclosures.

These studies are an important step to understanding the process clients go through when determining what to conceal versus disclose in therapy. Indeed, these are the first studies to really look at the process of disclosing from the client's perspective. 
However, the researchers note that there are a few limitations to the study. First, the small sample size, which was necessary due to the qualitative method, makes generalizability difficult (Farber et al., 2004, 2006). Additionally, most of the clients were in long-term psychodynamic psychotherapy, and so the researchers theorize that these clients may have had a greater appreciation for disclosure of secrets in the name of intrapsychic change. This type of study needs to be replicated with clients in other types of therapy. Finally, the researchers did not ask about specific disclosures, but rather, asked about the general experience of disclosing in therapy. Thus, they assessed tendencies related to disclosure versus how clients experienced specific disclosures.

Farber and Sohn (2007) compared disclosure in the therapeutic setting to disclosure in the context of marriage. Their purpose was to examine differences in selfdisclosure between situations in terms of the content and salience of what is disclosed. They also wanted to compare the relationship between disclosure and outcomes in each context.

Forty-eight married individuals who were currently in psychotherapy served as participants. Most were considered to be in long-term marriages $(M=16.1$ years, $S D=$ 13.1) and long-term psychotherapy ( $M=4.4$ years, $S D=6.7$ months). Participants completed the Disclosure-to-Therapist Inventory-III (DTI-III; Farber, Hall, \& Sohn, 1997), which consisted of questions regarding the level to which they disclosed on a variety of topics to their therapist. Each topic also had a corresponding salience rating that allowed the participant to rate the importance of each topic on a 5-point scale ( $1=$ minor, 5 = great). They also completed the Disclosure-to-Spouse Inventory, which was identical to the DTI-III, except that the word "spouse” was substituted for the word 
“therapist” in each item. Participants also completed questions regarding how successful they thought their therapy had been to date and identical questions regarding their marital success and satisfaction.

There was no difference between total disclosure to therapist and total disclosure to spouse (Farber \& Sohn, 2007). However, disclosure varied in content. Participants were more likely to discuss issues surrounding despair in therapy than in the context of marriage. They were more likely to disclose issues surrounding procreation and values to their spouses than to their therapists. For both marriage and therapy, issues related to intimacy, despair, and existentiality were rated as most salient. Narcissism, intimacy, and despair were rated high in salience, but were less likely to be discussed in the context of marriage than in the context of therapy, indicating that it was more difficult to discuss these important issues with one's spouse than with one's therapist. Issues surrounding sexuality were among the least disclosed and least salient in both relationships. The researchers speculated that sexuality may be considered taboo to talk about in all relationships and wondered if the low ratings may be due to shameful feelings.

The authors collapsed the 6 outcome questions for therapy and for marriage into one composite outcome score for each (Farber \& Sohn, 2007). For therapy, mean disclosure was a significant predictor of therapy outcome, while for marriage, both mean disclosure and mean discrepancy scores (the difference between a topic's salience and it's level of disclosure) were predictors of marriage outcome.

That despair was disclosed more in the therapy setting indicates that therapy may be a place that clients feel more comfortable engaging their negative affect (Farber \& Sohn, 2007). Additionally, the higher discrepancy ratings for spouses indicates that 
clients may be more likely to discuss certain important issues with their therapists than with their spouses. Although overall levels of disclosure were not different across relationships, participants disclosed differentially to their therapists versus spouses, speaking to the uniqueness of the therapeutic relationship as compared to personal relationships a client may have.

One limitation of the study is that marital satisfaction was assessed through an adapted therapy outcomes assessment. It is possible that marital outcomes should be judged differently than therapy outcomes (i.e. assessing for the role of marriage in reducing symptom severity may not be appropriate in the same way as assessing the role of therapy in reducing symptom severity). Additionally, on average, the participants rated their therapy and marriages positively. Perhaps these patterns do not hold for individuals with less successful marriages or less successful therapy. Finally, differences in outcomes may be found for clients in short-term therapy versus long-term therapy.

Saypol and Farber (2010) investigated the role that attachment style plays in client disclosure in psychotherapy. Since the therapeutic relationship is often viewed as an adult attachment relationship where the therapist acts as the client's secure base (see Farber, Lippert, \& Nevas, 1995), they hypothesized that attachment style may relate to the level of client disclosure and the types of feelings the client experiences before and after the disclosure.

Their sample consisted of 117 clients who were currently in therapy and had completed at least three sessions with their current therapist. Clients tended to be in longterm therapy $(M=36.37$ months, $S D=45.75)$. A number of the clients were therapists themselves (13.7\%) or were therapists-in-training (13.7\%), and clients tended to see 
psychodynamic therapists (54.7\%). Participants were recruited via advertisements in therapy offices and through listservs. Clients accessed an online survey, where they completed measures to assess their attachment style, their level of disclosure on a variety of topics, their feelings immediately before and immediately after a disclosure, and their attachment to their therapist.

The researchers found a positive correlation between secure attachment and level of disclosure $(r=.30, p<.01)$ and a negative correlation between dismissing attachment style and level of disclosure $(r=-.30, p<.01)$. There was no relationship between level of disclosure and either fearful or preoccupied attachment styles. These results remained even when controlling for length of time in therapy. A positive relationship also existed for strength of attachment to therapist and level of disclosure $(r=.47, p<.01)$. Clients with a secure attachment were more likely to experience more positive emotions $(r=.27$, $p<.01)$ and less likely to experience negative emotions $(r=-.24, p<.05)$ immediately after disclosing. Clients with a fearful attachment style were more likely to experience negative emotions prior to $(r=.28, p<.01)$ and following a disclosure $(r=.38, p<.01)$. Finally, there was no relationship between gender and attachment or level of disclosure, indicating that men and women were equally likely to disclose in psychotherapy.

Limitations of this study include the high number of therapists and therapists-intraining in the sample. These groups presumably have a high level of understanding of and commitment to the therapeutic process, which may not reflect the experiences of the average client population. Additionally, this study asked clients about disclosures in general, versus asking about specific disclosure events. Thus, their answers related to general tendencies and perhaps did not capture the differing experiences that one client 
may have depending on what s/he is disclosing.

Balmforth and Elliott (2012) used Comprehensive Process Analysis (CPA) to analyze a single client disclosure event in order to better understand what led to the disclosure and the impact it had on the client. The client, a 19-year-old EuropeanAmerican female, completed 19 sessions of Process-Experiential Therapy at a university research clinic. She was recruited as part of a larger study on using person-centered therapy to address crime-related PTSD. The client had experienced rape and attempted murder 5 years prior to beginning treatment. After each session, the client filled out the Helpful Aspects of Therapy form (Elliott, Slatick \& Urman, 2001; Llewelyn, 1988), which identifies the most and least helpful events in therapy and rates the helpfulness of the event on a scale from $1=$ extremely hindering to $9=$ extremely helpful (Balmforth $\&$ Elliott, 2012). She also filled out the Session Evaluation Questionnaire (SEQ; Stiles, 1980), which measures the depth and smoothness of the session, and the Revised Session Reaction Scale (RSRS) which assesses the most and least helpful reactions clients have in sessions. Finally, she filled out the Client Experiencing Scale (CEXP; Klein, Mathieu, Gendlin, \& Kiesler, 1969; Klein, Mathieu-Coughlan, \& Kiesler, 1986), which measures the client's participation level in therapy.

In the sixth session, the client disclosed that she had been molested as a child (Balmforth and Elliott, 2012). She identified this disclosure as the most helpful event that occurred in the therapy session because it was the first time she had ever talked about it, and she realized how the experience connected to other parts of her life. She rated the helpfulness of the event as an 8.5 (out of 9) on the helpfulness scale. A process analysis of therapist and client key speaking turns indicated that the client hinted at her secret 
through discussing the widespread prevalence of abuse in society. The therapist invited the client to disclose by asking if she had ever been abused, and the client accepted the invitation and disclosed her experience. An effects analysis revealed that after disclosing, the client turned her focus back to abuse in society, as if focusing on her own experience was too difficult. Even when the therapist tried to redirect her to her own experience, the client stayed at the broader level. The therapist repeatedly offered empathic statements, which the client initially did not acknowledge. However, eventually she heard his empathy and felt understood, and she linked her past experience of abuse with her current psychological state (Balmforth \& Elliot, 2012). She then went on to share more about the experience, including her anger towards her mother, whose boyfriend was the abuser. She exhibited an increase in participation in the session following the disclosure. At the end of the session, the client voiced her relief at having disclosed the experience. In the following session, however, she expressed a desire not to continue discussing the experience, asserting that it was a past issue and that she had already dealt with it. Although she briefly mentioned the experience in her mid-treatment interview and noted that it had an emotional impact on her, she did not explore it in therapy for the remainder of treatment. The researchers theorized that perhaps the client's disclosure had allowed her to integrate the experience into her self-schema. When treatment ended, the client's PTSD symptoms had lessened.

The researchers analyzed the significance indicators of the client's post-session measure responses using the cutoffs outlined in Elliott (1993) (Balmforth and Elliott, 2012). Of the 7 subscales, 6 were positive, and the measures had a mean indicator score of +.85 , indicating that according to the quantitative measures, the event was a helpful. 
Limitations of this study include the method of analysis. A single judge (the first author) completed the qualitative analysis, which was then audited by the therapist. Perhaps a team of judges would have been more reliable in analyzing the data. Additionally, the researchers acknowledge that CPA has never before been used to analyze a disclosure event (Balmforth \& Elliott, 2012). Finally, the client did not participate in a post-treatment interview, so much of what is known about the client's experience is derived from transcripts and the therapist's experience. Hearing about the impact of the event from the client would have facilitated a better understanding of the client’s experience.

Summary. The findings suggest that clients disclose a moderate amount in therapy (Farber \& Hall, 2002). Clients are most likely to discuss negative feelings and intimacy and least likely to discuss sexuality and procreation (Farber \& Hall, 2002). When compared to disclosure to a spouse, there was no different in overall disclosure, but clients were more likely to discuss despair in therapy and more likely to discuss procreation and their values with their spouses (Farber \& Sohn, 2007). Sexuality was least likely to be discussed in both therapy and marriage. Discrepancy scores between level of importance and level of disclosure were higher in marriage, indicating that difficult topics, such as issues related to despair and intimacy, may be harder to talk about to one's spouse than to one’s therapist (Farber \& Sohn, 2007).

Level of disclosure was found to be positively related to the working alliance, length of time in therapy, secure attachment, strength of attachment to therapist, and therapy outcome (Farber \& Hall, 2001, 2002; Farber \& Sohn, 2007; Saypol \& Farber, 2010). Level of disclosure was found to be negatively related to dismissing attachment 
style (Saypol \& Farber, 2010). There was no relationship between level of disclosure and either shame- or guilt-proneness (Farber \& Hall, 2002). There were no differences between men and women in terms of overall levels of disclosure, but some differences were found in the topics disclosed, with women more likely to discuss issues surrounding procreation (Farber \& Hall, 2002; Saypol \& Farber, 2010).

The findings also indicate a pattern of disclosure: Clients who self-disclose typically begin therapy with a somewhat positive view of self-disclosure (Farber et al., 2006). They feel ambivalent beforehand, afraid of the therapist's response. They experience anxiety before and vulnerability during the disclosure, but when they receive a supportive response, they experience positive feelings, such as pride and authenticity (Farber et al., 2004, 2006). A positive disclosure experience then leads to subsequent disclosures. However, Saypol \& Farber (2010) found that this pattern might vary depending on the client's attachment style. They found a positive relationship between secure attachment and positive feelings post-disclosure and a negative relationship between secure attachment and negative feelings post-disclosure. They found a positive relationship between fearful attachment and negative feelings prior to and following a disclosure.

An analysis of a single disclosure event by Balmforth and Elliott (2012) showed a slightly different pattern: The client hinted at the secret. The therapist invited the client to share the secret, and the client accepted the invitation and disclosed the secret. At first, the client did not acknowledge the therapist's attempts to engage her empathically. However, eventually, the client did respond favorably to the therapist's empathic remarks and gained insight. The client identified this as a meaningful event; however, she chose 
not to discuss it in subsequent sessions.

Finally, the findings indicate that clients hold primarily positive beliefs about disclosing (Farber et al., 2004). Most agreed that although disclosure is uncomfortable, it is important to disclose in therapy, and they did not regret their previous disclosures in therapy. However, most clients also continued to keep something from their therapists.

\section{Concealment and Disclosure of Secrets Outside of Therapy}

A number of other studies have looked at the process of concealing versus revealing secrets outside of therapy. These studies provide important insights into how individuals view their secrets and negotiate the decision of when and how to reveal secrets.

While numerous studies have shown that disclosure is linked to benefits, others indicate that secret holders do not always feel safe enough to reveal their secrets. Norton, Feldman, and Tafoya (1974) sought to identify what types of secrets were perceived to be more versus less risky to disclose. The researchers recruited 359 undergraduates in 20 communication classes to participate. While in class, each participant wrote down his/her biggest secret on a slip of paper. These slips of paper were then collected and the slips were redistributed to the class so that each participant held another participant's secret. One by one, each secret was read aloud, and the reader expressed how s/he would feel if the secret belonged to him/her.

Four judges independently classified the secrets, with an average agreement of .88. The majority of secrets were related to sex (27\%) or failure (16\%), with other secrets falling into the following categories: masking (9\%), drugs (4\%), defective relationships (4\%), goals and plans (4\%), violence and destruction (4\%), physical health 
(3\%), habits (3\%), mental health (2\%), ego vanity (2\%), loneliness (2\%), phobia (2\%), stealing (2\%), alcohol (2\%), and cheating (2\%) (Norton et al., 1974). Twelve percent of the secrets were coded as "nonsecrets," indicating that a number of students either did not have or did not feel comfortable listing a real secret.

Of the original 359 secrets, a subset of 49 secrets was created by selecting 15\% of the secrets from each category. One hundred ninety undergraduates rated the riskiness of disclosing each of these secrets using a 5 -point scale $(1=$ "extreme low risk" to $5=$ “extreme high risk"). Sexual secrets were among those rated most risky, with 4 of the 5 most risky secrets related to sex. This finding indicates that sexual secrets tend to be perceived as too risky to disclose, which may account for why the majority of secrets were sexual in nature.

Limitations of this study include the methodology. Hearing one's secret read aloud may seem risky in itself, and $12 \%$ of the participants did not write down actual secrets. Additionally, some participants may have shared secrets that felt safe, rather than to choosing to hear their biggest secrets read aloud. Perhaps collecting the secrets anonymously without reading them aloud would have facilitated a safer environment for sharing real and risky secrets. Additionally, the use of a college sample limits generalizability. It could be that college students have different types of secrets and perceive riskiness differently than do other populations.

Some studies have explored the ideal conditions for revealing secrets. Kelly and McKillop (1996) reviewed previous literature to identify positive and negative consequences of revealing secrets. They found that revealing secrets may lead to decreased physical and psychological health problems, may alleviate rumination on the 
secret, and can facilitate insight gains. However, they found that revealing a secret may lead to negative or unhelpful feedback and may be related to loss of power in some relationships. They recommended that an individual share a secret if it is causing him/her distress and if s/he has a confidante who can be trusted to keep the secret, is nonjudgmental, and can help the secret-holder gain new insight.

Studies have also looked at aspects of revealing secrets that are beneficial. Kelly et al., (2001) examined the roles of gaining insight and catharsis in whether or not a disclosure is deemed beneficial. In one study, 117 undergraduates from an introductory psychology class reflected on secrets they had previously shared and indicated whether or not they gained insight or catharsis in revealing them. They found that gaining catharsis was correlated with negative current views about the secret $(r=.19, p<.05)$, while gaining insight was correlated with positive current views of the secret $(r=.27, p<.05)$. The researchers also asked the participants to rate in order of importance certain characteristics of a good confidante. They rated these characteristics in the following order: will keep my secret, understands me, will not judge me, is able to help me, is similar to me, and has had similar experiences. Thus, it appears that a confidante who is discreet and nonjudgmental is most important to participants. Additionally, they found that undergraduates rated trustworthiness as significantly more important in a confidante than attractiveness or expertness.

In a second study in the Kelly et al. (2001) report, 98 undergraduate students from an introductory psychology class were assigned to one of three writing conditions: write about your secrets with the purpose of gaining insight, write about your secrets with the purpose of gaining catharsis, and write about your day (control). Each participant 
completed two 25-minute writing assignments in a 1-week period. Those who wrote about their secrets in an attempt to gain new insights showed significant increases in positive affect concerning their secret $(r=.25, p<.05)$, whereas undergraduates who wrote about their secrets with the aim of gaining catharsis and those in the control condition did not show any significant gains.

Limitations of these two studies include the use of undergraduate student samples. The student perspective may not generalize to a wider population. Additionally, the authors noted that participants in the insight condition in study 2 might have also gained catharsis through the process of writing about their secrets (Kelly et al., 2001). This might play a role in why participants experienced more positive gains in this condition.

Vrij et al. (2002) investigated aspects of secret keeping among college students. Seventy college students completed two rounds of questionnaires, four months apart from each other. Students filled out Rosenberg's (1965) self-esteem scale and the Satisfaction with Life scale (Diener, Emmons, Larson, \& Griffen, 1985), which assessed well-being. They also filled out multiple questions regarding secrets, including whether or not they were keeping a secret, their reasons for keeping a secret, what their most important secret was at the moment, the length of time they had kept the secret, the seriousness of the secret, the consequences of revealing the secret, to whom they had revealed the secret, and behavioral indicators of revealing the secret (Vrij et al., 2002). In round two, in addition to these questions, the students were also asked if they had informed anyone new about the secret since the first round, and how they felt after informing that individual. In round one, 41 of the 70 students reported having a secret and not revealing the secret because they wanted to avoid disapproval (Vrij et al., 2002). Three quarters of the 
group described their secrets as serious, and $61 \%$ reported thinking of the secret often.

There was a negative relationship between keeping a secret and emotional well-being, such that those keeping a secret were less emotionally well off than were those not keeping a secret (Vrij et al., 2002). Additionally, the seriousness of the secret was negatively correlated with self-esteem and physical wellbeing, such that the more serious the secret, the lower the level of self-esteem and physical well-being. However, although serious secrets were associated with lower life satisfaction, the less serious secret holders had higher levels of self-esteem and physical and social wellbeing than did those who did not keep a secret at all.

By round two, 12 participants had told someone new about their secret. A comparison between the groups that talked between rounds one and two versus those that did not showed that the talkers were more likely to keep their secrets for intrinsic motivation and that they believed themselves to be worse liars than those that did not tell their secret. Additionally, only four participants kept a secret that they had never told anyone, leading the authors to conclude that total secrecy is uncommon (Vrij et al., 2002).

Limitations of the study include the use of a college student sample. Since college students are relatively high achieving and high functioning, they may not keep the types of secrets that would significantly impact functioning. A different sample may have more serious secrets and thus, different results might be found. Additionally, there were relatively few participants in each category, and so the authors might not have had enough power to detect some of the associations that may or may not exist. Finally, the authors concluded that confiding in others did not prove beneficial for subjects, due to the 
finding that those who revealed their secrets to someone new between rounds one and two did not differ from those who did not reveal their secrets to anyone new. However, the authors also found that most of the participants had told someone else about their secret at some point in time. Therefore, it may be that telling someone new did not significantly impact the participants because they had already shared the secret previously with at least one person. It might be that sharing a secret is helpful, but that the number of people one shares with matters less than actually sharing it at least once.

Summary. In a non-client sample, over half kept secrets, and they did so mainly to avoid disapproval from others (Vrij et al., 2002). Those keeping a secret were less emotionally well off than were those not keeping a secret (Vrij et al., 2002). While keeping a serious secret was associated with lower self-esteem and physical wellbeing, keeping a not-so-serious secret was associated with higher levels of self-esteem and physical and social wellbeing (Vrij et al., 2002). This indicates that keeping a small secret may be healthy for individuals.

Revealing secrets may relate to positive changes, such as decreased physical and psychological health problems, alleviated rumination, and insight gains (Kelly \& McKillop, 1996). However, there is also some risk involved, and disclosing may also lead to unhelpful feedback from the confidante and loss of power in relationships. Types of secrets may vary in their perceived riskiness, with sexual secrets among those considered most risky (Norton et al., 1974).

When considering disclosing a secret, individuals value a confidante who is trustworthy, understanding, and nonjudgmental (Kelly \& McKillop, 1996; Kelly et al., 2001). Kelly and McKillop (1996) recommended that disclosures be restricted to these 
types of confidantes and that secrets be disclosed only if they are causing distress. Disclosing secrets for the purpose of gaining insight may be beneficial, but disclosing secrets for the purpose of catharsis may actually be detrimental (Kelly et al., 2001). Total secrecy seems to be uncommon, as most secret-keepers have shared their secret with at least one other person (Vrij et al., 2002).

\section{Theories}

A number of theorists have developed theories about secrets. These theories explain why secret keeping is linked to negative health consequences and why disclosing traumas and other concealed information is related to positive health consequences.

\section{Inhibition theory}

Inhibition theory hypothesizes that inhibiting one's thoughts, emotions, and behaviors, particularly as they relate to a traumatic event, can be stressful and ultimately leads to illness (Finkenaur \& Rime, 1998; Pennebaker, 1985; Pennebaker, 1997; Pennebaker \& Beall, 1986; Pennebaker, Kiecolt-Glaser, \& Glaser, 1988; Pennebaker \& Susman, 1988). Inhibiting behavior in the short term takes mental effort, which is indicated by changes in physiological activity. For instance, Pennebaker and Chew (1985) found that when undergraduates attempted to mislead the experimenter, there was a short boost in skin conductance levels. Inhibition may also lead to obsessive thoughts regarding the event, and so inhibition theory predicts that not talking about a traumatic event may be just as stressful (or more so) than the event itself (Pennebaker, 1985). Over time, the stress associated with inhibiting thoughts and behaviors is compounded. Thus, long-term inhibition is associated with stress-related illnesses, such as heart disease and cancer (Derogatis, Abeloff, \& Meliseratos, 1979; Pennebaker, 1985). However, 
disclosing thoughts and feelings, either through writing or talking, reduces autonomic activity. It is hypothesized that through expression, thoughts and feelings are reorganized in one's cognitive schema, allowing for integration of the traumatic event and a reduction in rumination and stress (Pennebaker, 1985). Thus, greater health and wellness is experienced. Informal interviews with professional polygraphers revealed that when a guilty suspect initially lies and then later tells the truth, there is a drastic reduction in physiological activity (e.g. heart rate) and the suspect appears much more relaxed and expressive, despite the fact that s/he has admitted to a crime (Pennebaker, 1985).

\section{Preoccupation model}

The preoccupational model of secrecy posits that in an effort to keep certain secrets, these bottled-up thoughts may become obsessive. Wegner, Schneider, Carter, and White (1987) found that when participants were told not to think of a white bear, they found themselves unable to suppress the thought, thinking about it almost as much as when they were instructed to actively think about it. Thus, actively suppressing a thought may make the thought overly accessible. Lane and Wegner (1995) introduced the idea of the preoccupation cycle. First, the individual engages in thought suppression, an attempt to force the thought out of his/her mind, in an effort to keep a secret. The individual then experiences an intrusion of the thought into his/her mind. This raises his/her anxiety level, and so the individual attempts to once again suppress the thought. This cycle of thought suppression and thought intrusion continues to repeat through a feedback loop such that each happens in response to the other (Lane \& Wegner, 1995). This cycle occurs each time the individual tries to suppress the thought, suggesting that only through revealing the secret thought will the individual experience mental peace. 
A number of studies have shown evidence for the model, including ones looking at populations with concealable stigmas (Lane \& Wegner, 1995; Major \& Gramzow, 1999; Smart \& Wegner, 1999; Wegner \& Erber, 1992; Wegner et al., 1987). For instance, Smart and Wegner (1999) found that women with eating disorders who roleplayed not having an eating disorder experienced higher levels of secrecy, thought suppression, and thought intrusion than did women with eating disorders who role-played having eating disorders or than did women without eating disorders in either role play condition. However, Kelly and Kahn (1994) actually showed a decrease in thought intrusion in college students who tried to suppress their own personal intrusive thoughts. They theorized that with practice, individuals might get better at suppressing unwanted thoughts. Thus, the preoccupation model may not fit in every situation.

\section{Self-presentational perspective}

In contradiction to these previous theories, which seek to explain negative consequences of secret keeping, self-presentational perspective theory asserts that it is actually beneficial for clients to keep some secrets from their therapists. Kelly (2000) theorized that when clients conceal negative aspects of themselves from their therapists, they are able to present a more desirable self-image in therapy. This favorable impression causes the therapist to view the client favorably, which in turn allows the client to view him/herself more favorably, ultimately leading to changes in the client's self-concept (Kelly, 2000). Thus, it is actually beneficial for clients to keep secrets from their therapists.

This theory helps to explain the Kelly (1998) findings that secret keeping was associated with lower symptomatology, after controlling for self-concealment. Other 
studies done on a non-clinical population have supported this theory (Kelly \& Rodriguez, 2007; Kelly \& Yip, 2006). For instance, Kelly \& Rodriguez (2007) videotaped 51 undergraduate students acting in an introverted manner and an extroverted manner and informed the participants that one video would be watched for training purposes and the other deleted. Those participants who were told their extroverted tape would be viewed rated themselves as more social than those who were told their introverted video would be viewed. Those who were told that their extroverted video would be viewed also sat closer to a confederate in the waiting room than did those who were told their introverted video would be viewed. These findings indicate that knowing how they would be viewed on the video impacted their view of themselves and influenced their behavior. However, the only other study that looked at secret keeping and symptomatology in a clinical population (Kelly \& Yuan, 2009) failed to replicate the Kelly (1998) finding. Supporters of Kelly’s theory suggest that self-presentation serves an adaptive purpose and allows the individual to avoid rejection and stigmatization (Piazza \& Bering, 2010). Critics of Kelly’s theory point out that findings regarding concealment in counseling and process and outcome measures have been mixed, with a number of studies suggesting that concealment may be detrimental or have no effect in therapy (Hill et al., 2000). While they agreed that clients are sometimes motivated to keep secrets by a fear of rejection from their therapist should they reveal their true selves, Hill et al. (2000) argued that not revealing secrets to one's therapist may make the client feel like an imposter and prevent important work from being done. Rather, they assert that healing in therapy comes from revealing difficult personal information and receiving acceptance from the therapist. This assertion is supported by client reports that although disclosure 
is difficult, it is valuable to the therapeutic process, whereas concealing inhibits the therapeutic process (Farber et al., 2004).

\section{Self-monitoring theory}

It may also be that certain clients feel more concern about their public appearance than do others. Self-monitoring refers to the extent to which someone engages in selfobservation and self-control in order to regulate his/her expressive behaviors and create a specific desired image (Snyder, 1974). Individuals who are high self-monitors are highly motivated and able to regulate and modify their behaviors in order to meet certain expectations of their environments (Gangestad \& Snyder, 2000). Self-presentation seems particularly important when high self-monitors are in relationships with a perceived power imbalance (Fuglestad \& Snyder, 2010). Given that the therapist could be seen as having more power in the therapeutic relationship, perhaps clients who are high selfmonitors feel pulled to present themselves favorably to their therapists. Low selfmonitors, on the other hand, tend to behave consistently regardless of their environment (Oyamot, Fuglestad, \& Snyder, 2010). They focus on establishing equal and authentic relationships with others (Fuglestad \& Snyder, 2010). Therefore, low self-monitors may focus less on self-presentation in therapy and more on forming a genuine and open therapeutic relationship.

\section{Fever model of disclosure}

Jourard (1974) described self-disclosure as a sign of a healthy personality, and also as a means through which health was achieved. Stiles (1987) compared one’s urge to disclose to a having a fever: Just as a fever is a symptom of infection, the urge to disclose is a symptom of psychological distress. When dealing with personal problems, 
distress builds up and becomes overwhelming for the individual. Through expressing the distress verbally, the individual experiences relief. However, Stiles also recommended that clients not be forced to disclose beyond their comfort level. Rather, each individual regulates his/her disclosure and knows what s/he needs, just as the body knows how to fight off the infection that brings about the fever.

Numerous studies have found level of disclosure to be correlated with distress level in clinical and healthy samples (Jacobson \& Anderson, 1982; McDaniel, Stiles, \& McGaughey, 1981; Stiles, Shuster, \& Harrigan, 1992; Rippere, 1977). For instance, Stiles et al. (1992) found that anxious college students were more disclosing when they spoke about their anxiety than when they spoke about a happy subject, indicating a need to talk about their distress.

\section{Negative reinforcement}

Operant conditioning refers to the voluntary adaptation of behaviors in order to maintain or avoid certain outcomes (Skinner, 1938). Through negative reinforcement, individuals learn to refrain from certain behaviors as a means of avoiding unwanted consequences. Researchers have shown that clients conceal secrets in an effort to avoid disapproval and rejection from their therapists (Derlega et al., 2002; Finkenaur \& Rimé, 1998; Seibold, 2008; Vrij et al., 2002). Whether this consequence is real or imagined, the anxiety clients feel at the idea of disclosing a secret is genuine, and these feelings of fear maintain the pattern of concealment (Kazdin, 2001). Therapy offers in-vivo exposure to the feared experience, placing clients in a situation where disclosure is encouraged and somewhat expected. When clients disclose and the feared consequence (rejection) does not occur, their need to avoid is minimized. As they continue to disclose without being 
rejected, the learned association between disclosure and rejection slowly fades (Kazdin, 2001).

Summary. Most theories related to concealment indicate that keeping secrets is harmful. Keeping in thoughts, behaviors, and feelings leads to stress and eventually illness (e.g. Pennebaker, 1985). The individual may start to ruminate on the issue, becoming obsessed and thinking about it more, even when s/he tries to put it from his/her mind (Lane \& Wegner, 1995; Pennebaker, 1985). The individual experiences a build-up of distress when s/he does not disclose, leading to urgency in disclosing (Stiles, 1987). The individual may be anxious to disclose because concealing ensures that s/he will not be rejected (Skinner, 1938). However, when the individual discloses in a therapy setting, s/he experiences relief (Stiles, 1987). If the therapist is accepting, the individual's association between disclosure and rejection will slowly start to weaken (Kazdin, 2001).

However, self-presentational theory asserts that keeping secrets is beneficial (Kelly, 2000). When the client presents him/herself in an ideal way, hiding the undesirable aspects of him/herself self, the therapist accepts the client, the client experiences self-acceptance. Critics of this theory point out that, while it may be necessary to hide undesirable aspects of the self in day-to-day life, true healing in therapy comes from disclosing and being accepted by the therapist (Hill et al., 2000). Selfmonitoring theory speculates that clients may behave differently depending on whether they are high or low self-monitors. High self-monitors may focus more on selfpresentation, while low self-monitors may behave more authentically (Oyamot, Fuglestad, \& Snyder, 2010). 


\section{Chapter 3: Statement of the Problem}

Although secrets have been investigated in several studies, we need to know more about how clients navigate the decision of whether to disclose or conceal a secret and how they experience the processes of concealment and disclosure. Furthermore, the few studies that have looked at the disclosure process (e.g. Farber et al., 2004, 2006) have examined general tendencies related to disclosure (i.e. how one typically feels when s/he discloses), rather than how clients felt and experienced specific secrets that were either concealed or disclosed.

In addition, the mixed findings related to concealment indicate that we still need to know more about secrets and their relationship to other processes in therapy. Studies focused on concealment have found some evidence that keeping secrets is beneficial and some evidence that it is harmful (Hill et al., 1993; Kelly, 1998; Kelly \& Yuan, 2009; Regan \& Hill, 1992). For instance, Regan and Hill (1992) found that things left unsaid in session that were related to behaviors and cognitions were negatively correlated with session satisfaction and depth, while things left unsaid that were related to emotions were positively correlated with session satisfaction, depth, and symptom change. However, since what clients actually discussed in therapy was not measured, it is unclear whether these findings relate more to what was withheld or to what was disclosed in therapy (i.e. when more emotions were withheld, perhaps more emotional content was also being shared). In keeping with that logic, perhaps when secrets are being concealed, other secrets are also being disclosed. Perhaps as long as the client openly discusses a few important issues in therapy, it does not negatively impact treatment for the client to also be keeping one or more secrets (Farber, 2003). 
In this study, I aim to investigate client experiences related to concealing and disclosing specific secrets. We first need to establish whether clients do indeed choose to disclose some secrets while concealing others. Additionally, we need to know more about what secrets clients choose to conceal versus disclose and how they reach these decisions. Finally, if clients are both concealing and disclosing secrets, we need to better understand how this impacts the therapeutic relationship and treatment outcome.

I chose to posit research questions instead of hypotheses because the existing research has not focused specifically on the disclosure of secrets.

Given that studies focused on concealment have shown that a significant number of clients conceal secrets from their therapists (e.g. Kelly, 1998) and studies focused on disclosure have indicated that clients disclose distressing personal information (e.g. Farber et al., 2004), it seems plausible that clients choose to conceal some secrets and reveal others. In this study, I addressed the following question:

Research Question 1: How many clients have concealed and/or disclosed at least one secret in therapy?

Researchers have shown that clients are most likely to conceal secrets about relationship difficulties, sexual issues, and feelings of failure, and that clients are most likely to disclose feelings about self and others (Farber, 2003; Hall \& Farber, 2001; Hill et al., 1993). Perhaps certain types of secrets are easier to disclose than others, given that certain types of secrets (such as sexual secrets) are perceived as more risky than others (Norton et al., 1974). In this study, I expanded on what is currently known regarding what clients conceal versus disclose by addressing the following question:

Research Question 2: What types of secrets are concealed versus disclosed? 
Studies on client concealment have shown that clients often keep secrets in therapy due to shame, embarrassment, and a fear of the therapist's reaction (Farber et al., 2004; Hill et al., 1993; Kelly, 1998; Kelly \& Yuan, 2009). One study on disclosure showed that clients expressed "a desire to unburden themselves," which directly led to the disclosure of secrets in therapy (Farber et al., 2004, p. 344). Given that clients' reasons for keeping versus disclosing salient personal issues have been examined in only one study (Farber et al., 2004), I sought to better understand the motivations for concealment versus disclosure of secrets through asking the following:

Research Question 3: What are the reasons for concealing versus disclosing secrets? Kelly (1998) found that clients imagined they might gain insight, get catharsis, and give their therapists important information if they were to disclose their secrets. In the current study, I seek to expand on the limited knowledge regarding what clients imagine they would gain from disclosing secrets and also to determine if what clients believe they would gain is actually what clients reporting gaining when they disclosure. Therefore, I addressed the following question in this study:

Research Questions 4: How do the gains clients imagine they would get by sharing their undisclosed secrets with their therapists compare to the gains they actually received by revealing secrets to their therapists?

Farber et al. (2004) found that clients found it easier to self-disclose when there was a strong therapeutic alliance and when the therapist was accepting of the client. They also found that past disclosures that have gone well might positively influence one's decision to disclose. In this study, I sought to replicate and further these findings via the following question: 
Research Question 5: What do clients believe might influence them to disclose their currently undisclosed secrets?

Farber et al. (2004) found that clients reported higher levels of positive emotions than negative emotions after disclosing a secret to their therapist. Farber et al. (2006) found that clients reported feeling anxiety prior to disclosing a secret, but experienced feelings of relief and authenticity following the disclosure. Studies of secrets in therapy indicate that feelings of shame and embarrassment accompany secrets (Hill et al., 1993; Kelly, 1998). However, these feelings have never been directly measured, nor have feelings regarding concealment versus disclosure of secrets been measured and compared in any single study. Therefore, I addressed the following question:

Research Questions 6: On average, do clients differ in the extent to which they feel positive versus negative emotions when they think about their experience immediately after having disclosed a secret versus when they think about the secrets they are concealing?

Balmforth and Elliott (2012) found that although a client perceived a disclosure event as highly helpful immediately following the session in which she disclosed, she did not wish to discuss the topic further in subsequent sessions. Since the client did not complete a post-session interview, it is unclear if her feelings about the disclosure event changed over time. Pennebaker and Beall (1986) found that participants who wrote about a traumatic event reported negative feelings immediately following the writing activity, but they experienced a long-term decrease in health problems. These results suggest that there were positive long-term effects, even if the initial effects were negative. Farber et al. (2006) found that clients experienced higher levels of positive emotions immediately 
following a disclosure. We need to know more about how emotions regarding the disclosure continue to change after the disclosure event occurs. Thus, I asked the following question:

Research Question 7: On average, do clients differ in the extent to which they feel positive versus negative emotions when they think about their experience immediately after having disclosed a secret versus when they reflect on their current feelings about the secret they disclosed earlier?

Previous studies have found a negative relationship between concealment and the working alliance and a positive relationship between disclosure and the working alliance (Farber \& Hall, 2002; Kelly \& Yuan, 2009). However, it is unclear whether one of the relationships is stronger or how the relationships may differ if a client is disclosing some information and concealing other information. Additionally, no studies have looked specifically at how concealment and disclosure of secrets relate to the bond subscale of the working alliance, which pertains to the personal connection between client and therapist. Hence, I asked the following question:

Research Question 8: Is there a difference in the relationship between concealment and working alliance bond versus disclosure and working alliance bond?

Previous studies on concealment and disclosure in therapy have not looked at their relationships to the real relationship. The real relationship includes the degree to which the client feels understood and "seen" by the therapist (Kelley, Gelso, Fuertes, Marmarosh, \& Lanier, 2010). It makes sense, given the personal nature of secrets, that concealment and disclosure would be related to the real relationship. Since the real relationship is positively related to the working alliance, it seems likely that the strength 
of the real relationship will correlate positively with disclosure and negatively with concealment. However, lack of previous research makes it difficult to theorize whether there will be a differential association.

Research Question 9: Is there a difference in the relationship between concealment and the real relationship versus disclosure and the real relationship?

Previous findings regarding the relationship between concealment and treatment progress or outcome have been mixed, with one study showing a positive relationship between concealment and symptom change (Kelly, 1998), and another showing no relationship between concealment and symptom change (Kelly \& Yuan, 2009). Additionally, Farber and Saypol (2010) found that disclosure was positively related to treatment outcome. However, that study examined disclosures on a variety of topics, and so it is unclear whether examining disclosures specifically related to secrets will yield the same results. Given that many clients may be concealing some secrets and disclosing others, it may be that either concealment or disclosure of secrets may be more strongly related to treatment progress. In this study, I address the following question:

Research Question 10: Is there a difference in the relationship between concealment and treatment progress versus disclosure and treatment progress? 


\section{Chapter 4: Methods}

\section{Design}

I used a survey design for this study. I was interested in the participants' inner experience in therapy, which is not directly observable. Therefore, surveying the participants about their inner experience was the only way to acquire this information.

\section{Participants}

I conducted a power analysis for a paired sample t-test to determine the ideal sample size for the current study. In order to detect a medium effect size (.50), with an alpha of .05, 45 participants were needed. Due to the multiple statistical tests being conducted, I aimed for a sample size of 100.

The study included 101 participants (23 male, 77 female, 1 unknown; 71 white, 6 black, 7 Hispanic, 13 Asian, 3 multiracial, 1 unknown). Age ranged from 19 to 75 ( $M=$ 36.97, $S D=13.05)$. All participants had completed at least 8 sessions with their current therapists and were in individual psychotherapy. For those participants who listed the number of sessions in terms of number of years in therapy, the number of sessions was calculated by assuming 45 sessions per year (e.g. 3 years became 135 sessions). The average number of sessions was $107.28(S D=203.57$, range 8 to 1,350$)$. In terms of education level, 3 participants had some college (3\%), 35 had a bachelor's degree (35\%), 48 had a master's degree (48\%), 13 had a Ph.D. (13\%), and 2 were unknown (2\%), indicating that this was a well-educated sample. Twenty-one participants were therapists or therapists-in-training (21\%), 73 were not (72\%), and 7 were unknown (7\%).

Forty-one participants were seeing a male therapist (41\%), 59 were seeing a female therapist (58\%), and 1 was unknown (1\%). In terms of theoretical orientation of 
the therapists, as reported by the participants, 17 therapists were psychodynamic (17\%), 22 were cognitive-behavioral (22\%), 12 were person-centered (12\%), 11 were eclectic (11\%), 8 were other (8\%), 30 were not sure (29\%), and 1 was unknown (1\%).

An additional 12 participants did not meet eligibility requirements. Sixty-eight participants started the survey but did not finish. However, of those dropouts, only 7 started the actual questionnaire. The others dropped out after completing the eligibility questionnaire $(\mathrm{N}=11)$, after giving informed consent $(\mathrm{N}=8)$, or before responding to the informed consent question $(\mathrm{N}=42)$.

\section{Measures}

The Working Alliance Inventory-Short Revised (WAI-SR; Hatcher \& Gillaspy, 2006) is a 12 -item measure with a 5 -point scale that ranges from $1=$ seldom to $5=$ always. This measure was adapted from the original Working Alliance Inventory (WAI; Horvath \& Greenberg, 1989), which consisted of 36 items. The measure assesses the quality of the therapeutic working alliance on three subscales: bond, tasks, and goals. The reliability of the measure (Cronbach’s alpha) has been demonstrated to be .90 (Hatcher \& Gillapsy, 2006). Its test-retest reliability has been demonstrated to be .73 (Martin, Garske, \& Davis, 2000).

For this study, only the bond subscale was used. Its reliability has been demonstrated to be .89 (Hatcher \& Gillapsy, 2006). The subscale has been found to correlate with the Penn Helping Alliance Questionnaire $(r=.59)$ (HAQ; Alexander \& Luborsky, 1986) and the California Psychotherapy Alliance Scale ( $r=.65)$ (CALPAS; Marmar, Horowitz, Weiss, \& Marziali, 1986) (Hatcher \& Gillaspy, 2006). It is correlated also with treatment outcome, including client and therapist ratings of improvement $(r=$ 
.40 and $r=.14$ respectively) (Hatcher \& Gillaspy, 2006). Internal consistency (Cronbach’s alpha) for this data set was .87.

The Real Relationship Inventory (RRI; Kelley, Gelso, Fuertes, Marmarosh, Lanier, 2010) measures the personal relationship between the client and therapist. It consists of two 12-item subscales (Realism and Genuineness) rated on 5-point scales ( $1=$ strongly agree, 5 = strongly disagree). Reliability (Cronbach’s alpha) has been demonstrated to be .90 for realism, .91 for genuineness, and .94 for the total score. Testretest reliability has been demonstrated to be .88 for genuineness, .84 for realism, and .87 for the total score. The RRI is positively related to ratings of the working alliance ( $r=$ $.79)$ and therapist ratings of the real relationship $(r=.60)$ and negatively related to client avoidant attachment $(r=-.40)$ (Kelley et al., 2010, Marmarosh, Gelso, Markin, Majors, Mallery, \& Choi, 2009). This study used a 12-item version of the measure that was first used in Hill et al. (2013), which consists of the 12 items believed to best encompass the theoretical components of the measure. The 12-item measure correlates .91 with the longer measure (Hill et al., 2013). Internal consistency (Cronbach’s alpha) for the present study was .88 .

The Client Outcome Measure (COM; Gelso \& Johnson, 1983) is a 4-item measure with a 7 -point scale that ranges from $1=$ much worse to $7=$ much improved. It assesses client progress in therapy in terms of changes in feelings, behaviors, understanding, and overall change (Gelso et al., 2012). The reliability of the measure (Cronbach’s alpha) has been demonstrated to be .92 (Gelso et al., 2012). The measure has been found to correlate with therapist-rated outcome $(r=.38)$, client and therapist ratings of the real relationship ( $r=.49$ and .29 respectively), and client secure attachment 
to therapist ( $r=.59$ ) (Fuertes et al., 2007; Gelso et al., 2012). Internal consistency for the present study was .90 .

The Outcome Rating Scale (ORS; Mill \& Duncan, 2000) measures treatment outcome by assessing how the client has been functioning over the past week in individual, interpersonal, social, and global areas of his/her life. The measure consists of 4 items, which are measured on a $10 \mathrm{~cm}$ visual analog scale (VAS) ranging from negative (left) to positive (right) (Janse, Boezen-Hilberdink, van Dijk, Verbraak, \&

Hutschemaekers, 2013). Clients place a mark on the line to represent their level of functioning, and the mark is rounded to the closest millimeter to determine the numerical response to each item (range from 0-10) (Janse et al., 2013). Internal consistency (Cronbach’s alpha) has been demonstrated to be .90, and test-retest reliability was been shown to be .66 (Campbell \& Hemsley, 2009). The measure has been shown to be correlated with the Outcome Questionnaire-45 ( $r=-.74)$, the Quality of Life Scale ( $\mathrm{r}=$ .74), the Rosenberg Self-Esteem Scale $(r=.66)$, and the General Perceived Self-Efficacy Scale $(r=$.53) (Campbell \& Hemsley, 2009). Internal consistency (Cronbach’s alpha) for the present study was .91 .

The Disclosure of Secrets Questionnaire was developed for the present study based on past research. Secrets were defined for the participant as "life experiences, personal facts, thoughts, or feelings that you intentionally do not disclose.” Disclosure of secrets was assessed by asking direct questions about the secrets participants have disclosed to their therapist. Specifically, the participant was asked: “Do you have any secrets that you have disclosed to your therapist?” The participant was asked to think about one secret that s/he has disclosed to the therapist and to answer a number of follow- 
up questions about that secret. Participants were asked to "Please select all categories that best describe this secret.” A checklist included the following categories: secretly desiring the wrong person, relationship difficulties, sexual secret, health problem, failure, drug or alcohol use, lying, cheating, law-breaking, and other. These categories are the same as those used in Kelly and Yuan (2009) and were based on open-ended responses from Kelly (1998). Three other categories not present on Kelly and Yuan’s (2009) checklist were also added: sexual orientation, eating habits and self-harm. The participants were allowed to select multiple categories and could enter in their own response if they selected "other."

Participants were also given a checklist with the instructions: "From the checklist below, please select the reasons that best fit why you decided to share this secret with your therapist. Check all that apply.” The checklist included the following categories: I trust my therapist, My therapist responded positively to a smaller secret, I told someone else about the secret first which prompted me to tell my therapist, Keeping the secret became too burdensome, I felt like keeping the secret was preventing me from making progress in therapy, My therapist asked me directly about it, I thought I would benefit from sharing the secret, I want my therapist to know the real me, and other. The participants were permitted to select multiple categories and could enter in their own response if they selected "other."

Participants were given a checklist with the instructions: "From the checklist below, please select the options that best fit what you think you gained from sharing your secret with your therapist. Check all that apply.” The checklist included the following categories: get more feedback- insight, get emotions out- relief, find a solution, give the 
therapist information s/he needs, nothing, or other. These categories are taken from the categorization of open-ended data in Kelly (1998). The participants were able to select multiple categories and could enter in their own response if they selected "other.”

Finally, for each disclosed secret, participants were asked to rate the extent to which they felt four positive emotions (proud, authentic, safe, and relieved) and seven negative emotions (ashamed, vulnerable, exhausted, sad, anxious, angry, and guilty) immediately after disclosing the secret to their therapist, as well as currently when they think about the disclosure. These items were measured on a 7-point scale, where $1=\mathrm{a}$ little, $4=$ somewhat, and $7=$ to a great extent. Ten of these items were originally used in Farber et al. (2004), and an eleventh emotion (guilt) was added in Saypol and Farber (2010). A factor analysis by Saypol and Farber (2010) revealed that the items do load onto two factors, a negative emotions factor and a positive emotions factor, and that the two factors do not correlate highly with each other, indicating that clients may hold conflicting emotions simultaneously. Cronbach’s alpha was demonstrated to be .78 for the negative emotions and .71 for the positive emotions (Saypol \& Farber, 2010).

I conducted factor analyses on the 11 emotions items to determine whether they clustered similarly in the current study. I conducted one factor analysis on the items related to emotions felt immediately after disclosing a secret and a second factor analysis on the items related to current emotions regarding the disclosure. Tabachnick \& Fidell, (1996) suggested that the Kaiser-Meyer Olkin index should be $>.60$ in order to warrant a factor analysis. For items pertaining to feelings immediately following disclosure, the Kaiser-Meyer Olkin Index $(\mathrm{KMO})$ was $.75, \mathrm{X}^{2}=283.11(\mathrm{~N}=86), p=.00$, indicating that the items in the scale were sufficiently intercorrelated to justify a factor analysis. For 
items pertaining to current feelings about the disclosure, the Kaiser-Meyer Olkin Index was .80, $\mathrm{X}^{2}=400.97(\mathrm{~N}=86), p=.00$, indicating that these items were also sufficiently intercorrelated to justify a factor analysis. Since Saypol and Farber (2010) found that the items loaded onto two factors, I chose to limit the current factor analyses to two factors. I used principle axis factoring as the extraction method. Since Saypol and Farber (2010) found that the two factors were not highly correlated, I selected the varimax rotation, which is an orthogonal rotation and should be used when the subscales are not correlated.

Both factor analyses showed that items loaded clearly onto one of two factors, and that each item loaded $>.41$ onto its respective factor. The first factor $(7$ items, initial feelings regarding disclosure $\alpha=.82$; current feelings about disclosure $\alpha=.86$ ) relates to negative emotions, and the second factor (4 items, initial feelings regarding disclosure $\alpha$ $=.62$; current feelings about disclosure $\alpha=.78$ ) relates to positive emotions. The loadings are consistent with those found in Saypol \& Farber (2010). Table 1 shows the factor loadings for the emotion scale items.

The Secrets Questionnaire was also developed for the present study based on past research. Secret keeping was assessed through direct questions about the participant's secrets. The participant was asked: "Are there any secrets that you have not disclosed to your therapist that seem relevant to your therapy?” The participant was asked to think about one secret that s/he had not disclosed to the therapist, and a number of follow-up questions were asked about that secret. Participants were asked to "Please select all categories that best describe this secret.” A checklist included the following categories: secretly desiring the wrong person, relationship difficulties, sexual secret, health problem, failure, drug or alcohol use, lying, cheating, law-breaking, and other. These categories 
Table 1.

Factor Loadings for Emotion Scale

\begin{tabular}{|c|c|c|c|c|c|c|}
\hline & \multicolumn{2}{|c|}{$\begin{array}{l}\text { Initial Feelings About } \\
\text { Disclosure }\end{array}$} & \multicolumn{2}{|c|}{$\begin{array}{l}\text { Current Feelings About } \\
\text { Disclosure }\end{array}$} & \multicolumn{2}{|c|}{$\begin{array}{l}\text { Current Feelings About } \\
\text { Concealment }\end{array}$} \\
\hline & Negative & Positive & Negative & Positive & Negative & Positive \\
\hline Ashamed & .77 & -.28 & .71 & -.22 & .70 & .11 \\
\hline Vulnerable & .76 & -.05 & .59 & .03 & .52 & -.11 \\
\hline Sad & .66 & -.06 & .76 & .02 & .72 & -.01 \\
\hline Anxious & .65 & .07 & .86 & -.23 & .68 & .03 \\
\hline Guilty & .64 & -.30 & .67 & -.17 & .69 & .04 \\
\hline Exhausted & .51 & .13 & .65 & -.11 & .54 & -.16 \\
\hline Angry & .41 & -.14 & .46 & -.18 & .44 & .15 \\
\hline Relieved & .16 & .57 & .01 & .66 & -.06 & .55 \\
\hline Authentic & -.06 & .55 & -.30 & .71 & .08 & .46 \\
\hline Proud & -.10 & .51 & -.04 & .62 & .06 & .67 \\
\hline Safe & -.18 & .51 & -.22 & .71 & -.05 & .39 \\
\hline
\end{tabular}


are the same as those used in Kelly and Yuan (2009) and were based on open-ended data from Kelly (1998). Three other categories not present on Kelly and Yuan’s (2009) checklist were also added: sexual orientation, eating habits and self-harm. The participants were allowed to select multiple categories and could enter in their own response if they selected “other.”

Participants were given a checklist with the following instructions: "From the checklist below, please select the reasons that best fit why you have not shared your secret with your therapist. Check all that apply.” The checklist will include the following categories: I am afraid to express my feelings, I am too ashamed or embarrassed, Revealing the secret would show my therapist how little progress I have made, There was no time, I would not tell anyone, I am not motivated to address the secret, I am being loyal to another person, and other. These categories were used by Kelly and Yuan (2009) and were based on qualitative data from Kelly (1998). The participants were able to select multiple categories and could enter in their own response if they selected “other.”

Participants were given a checklist with the following instructions: "From the checklist below, please select the options that best fit what you think you would gain from sharing this secret with your therapist. Check all that apply.” The checklist will include the following categories: get more feedback- insight, get emotions out- relief, find a solution, give the therapist information s/he needs, nothing, or other. This checklist is based on the categorization of qualitative data from Kelly (1998). The participants were allowed to select multiple categories and could enter in their own response if they selected “other.” 
Participants were also asked the following question: "Under what circumstances might you decide to share this secret with your therapist?” A checklist provided the following responses: If I trusted my therapist more/had a better relationship with my therapist; If I had more sessions with my therapist; If my therapist responded positively to a smaller secret; If I told someone else about the secret first; If keeping the secret became too burdensome; If I felt like keeping the secret was preventing me from making progress in therapy; If my therapist asked me more directly about it; Under no circumstances would I share my secret with my therapist; and other. The participants were able to select multiple categories and could enter in their own response if they selected “other.”

Finally, for each secret, participants were asked to rate the extent to which they felt four positive emotions (proud, authentic, safe, and relieved) and seven negative emotions (ashamed, vulnerable, exhausted, sad, anxious, angry, and guilty) when they thought about not having shared the secret with their therapist. These items were measured on a 7-point scale, where $1=$ a little, $4=$ somewhat, and $7=$ to a great extent. As mentioned above, these items were previously used in Farber et al. (2004) and Saypol \& Farber (2010) to assess feelings immediately prior to and after a disclosure in therapy. Cronbach's alpha was demonstrated to be .78 for the negative emotion subscale and .71 for the positive emotion subscale (Saypol \& Farber, 2010).

I conducted a factor analysis on the 11 emotions items to determine whether they clustered similarly when used to assess feelings related to concealment. The KaiserMeyer Olkin Indices (KMO) was .61, indicating that the items in the scale were sufficiently intercorrelated to justify a factor analysis.. Since Saypol and Farber (2010) 
found that the items loaded onto two factors, I forced the factor analysis into two factors. I used principle axis factoring as the extraction method. Since Saypol and Farber (2010) found that the two factors were not highly correlated, I selected the varimax rotation, which is an orthogonal rotation and should be used when the subscales are not correlated. The analysis showed that items loaded clearly onto one of two factors, and that each item loaded $>.39$ onto its respective factor. The first factor (7 items, $\alpha=.80$ ) relates to negative emotions, and the second factor ( 4 items, $\alpha=.51$ ) relates to positive emotions. Table 1 shows the factor loadings for the emotions scale items.

\section{Procedure}

Participants were recruited using multiple methods. Initial recruitment efforts focused on contacting therapists to request assistance in recruiting one of their clients. Lists of state-licensed members were obtained for three divisions of the American Psychological Association: the Society of Counseling Psychology (Division 17), Psychotherapy (Division 29), and Psychologists in Independent Practice (Division 42). From these lists, every third member was contacted. If a selected member did not have contact information listed, the next member on the list with available contact information was selected. Additionally, 7 therapists-in-training working at a community clinic at the University of Maryland and 25 adjunct faculty members in the Counseling Psychology program at the University of Maryland were contacted. A total of 1,964 therapists were contacted. Of those therapists, 106 did not have current email addresses and 43 responded to say they were ineligible (e.g. not seeing clients). Thus, a total of 1,815 eligible therapists were contacted. 
Therapists received a personally addressed email that explained the nature of the study and asked that they assist in recruitment by giving a flyer about the study to the next client they saw. They were also invited to participate in the study themselves if they were clients. A flyer was attached to the email and was also available for download via a Qualtrics link included in the email. Therapists were asked to reply whether or not they chose to participate in recruitment. Those who did not reply received up to two reminder emails. Of the therapists contacted, 41 (2.3\%) responded that they would contact a client and $18(1.0 \%)$ declined to participate. There was no response from 1,756 therapists (96.7\%) after three emails.

Since this method of recruitment did not yield enough participants, additional recruitment methods were employed in an effort to contact clients directly. Sixteen counseling psychology graduate training programs were contacted via emails to their training directors. The emails requested that the program directors forward the invitation to participate in the study to their current students. Of those programs, four forwarded the information along to students (25\%). Additionally, two announcements were made on a listserv for faculty, staff, and graduate assistants at the University of Maryland. Flyers were also handed out in an upper-level Psychology class. And finally, snowballing methods were implemented in order to contact acquaintances known to be in therapy. An email was sent to each individual, inviting them to participate and to forward along the invitation to anyone else they believed might be interested.

The study was presented as a survey regarding what clients choose to say and not say in psychotherapy, and the participants were advised to complete the questionnaire in a private location in order to ensure confidentiality. In order to qualify, participants 
needed to be in individual therapy at the time of participating and to have completed at least eight sessions with their therapist. Participants connected to a Qualtrics survey via a secure link. First, they reviewed an informed consent form. They indicated consent by clicking the "I agree" option and continuing on to the survey. Next, participants completed a short questionnaire to verify eligibility. Those who did not meet the inclusion criteria were directed to a debriefing indicating that they did not meet the required criteria for participation. Those who met the inclusion criteria completed the WAI-bond, the RRI, the COM, the ORS, the Secrets Questionnaire, and the Disclosure Questionnaire. These were presented in random order to control for any effects of the order of measures, but the Disclosure Questionnaire was always presenting right before the Secrets Questionnaire. Finally, they filled out the demographics form. Once the measures were completed, participants received a description of the study and resources to contact if they experienced any distress while filling out the measures. Participants were then invited to send a blank email to an email address created by the principal investigator in order to be entered into a raffle to win one of three \$25 Amazon.com gift cards. Raffle winners were selected at random and contacted via email upon completion of data collection. 


\section{Chapter 5: Data Analyses}

\section{Preliminary Analysis}

A total of 103 participants, all of whom had completed at least eight sessions of psychotherapy, completed the study. Of those who completed the questionnaire, one case was dropped because the participant had seen her therapist for only 6 sessions, and a second case was dropped because the participant did not follow the directions when completing the questionnaire. Thus, all analyses were conducted on the remaining 101 participants.

There was demographic information missing from some participants. One participant was missing all demographic information. In addition, 19 participants failed to indicate whether or not they were a therapist or a therapist in training due to an error in the qualtrics program that was resolved early on in data collection. I was able to infer the response to this question using other demographic information for all but 7 participants.

Data were reasonably normally distributed, with skewness values for all measures falling between -1 and 1 (anything outside that range indicates skewness). Furthermore, from examining the plots of the data, no outliers were identified in the sample. Means, standard deviations, internal consistency values, and intercorrelations of all measures are presented in Table 2.

Independent sample t-tests were conducted to test whether there were differences between male and female participants. Results indicated that male participants were more likely than female participants to be concealing a secret, $t=2.12, p<.05$. There were no other differences based on gender. Additionally, independent sample t-tests 
Table 2

Means, Standard Deviations, Internal Consistency and Correlations of all Measures

\begin{tabular}{|c|c|c|c|c|c|c|c|c|c|c|c|c|c|}
\hline Measure & M & $\mathrm{SD}$ & $\alpha$ & 1 & 2 & 3 & 4 & 5 & 6 & 7 & 8 & 9 & 10 \\
\hline 1. RRI & 3.90 & .54 & .88 & & & & & & & & & & \\
\hline 2. WAI- Bond & 4.08 & .78 & .87 & $.69 * *$ & & & & & & & & & \\
\hline 3. COM & 5.97 & .84 & .90 & $.63 * *$ & $.48 * *$ & & & & & & & & \\
\hline 4. ORS & 6.26 & 2.09 & .91 & $.23 *$ & .13 & $.47 * *$ & & & & & & & \\
\hline $\begin{array}{l}\text { 5. Neg Emotion- } \\
\text { Concealment }\end{array}$ & 3.80 & 1.23 & .80 & .15 & .12 & .02 & -.14 & & & & & & \\
\hline $\begin{array}{l}\text { 6. Pos. Emotion- } \\
\text { Concealment }\end{array}$ & 2.31 & .87 & .51 & -.01 & -.21 & .19 & .12 & .00 & & & & & \\
\hline $\begin{array}{l}\text { 7. Neg. Emotion- } \\
\text { Initial Disclosure }\end{array}$ & 3.87 & 1.38 & .82 & -.15 & -.08 & -.01 & -.18 & $.34^{*}$ & .02 & & & & \\
\hline $\begin{array}{l}\text { 8. Pos. Emotion- } \\
\text { Initial Disclosure }\end{array}$ & 4.07 & 1.17 & .62 & $.26^{*}$ &. $.23^{*}$ & .19 & .20 & .11 & .00 & -.15 & & & \\
\hline $\begin{array}{l}\text { 9. Neg. Emotion- } \\
\text { Disclosure Now }\end{array}$ & 2.35 & 1.20 & .86 & $-.37 * *$ & -.21 & $-.25 *$ & $-.33 * *$ & .18 & -.05 & $.69 * *$ & $-.25^{*}$ & & \\
\hline $\begin{array}{l}\text { 10. Pos. Emotion- } \\
\text { Disclosure Now }\end{array}$ & 4.55 & 1.42 & .78 & $.32^{* *}$ & $.21^{*}$ & $.37 * *$ & $.32 * *$ & .28 & .13 & -.04 & $.75^{* *}$ & $-.28 * *$ & \\
\hline
\end{tabular}

$* \mathrm{p}<.05 .{ }^{* *} \mathrm{p}<.01$. 
were conducted to test whether there were differences between therapists or therapists-intraining and non-therapists. Results indicated that therapists and therapists-in-training were more likely than non-therapists to have disclosed a secret, $t=1.99, p=.051$. Therapists and therapists-in-training also had higher scores on the ORS, indicating higher levels of functioning over the past week than non-therapists. Additionally, therapists and therapists-in-training reported a higher level of positive emotions related to concealing a secret than did non-therapists, $t=-2.86, p<.01$. For analyses involving disclosure and the ORS, I ran the analyses both controlling for therapist status and without controlling for therapist status. Since controlling for therapist status did not alter the results of the analyses, I opted not to control for it. A comparison of the analyses involving the positive emotion subscale with and without therapists included in the sample showed no difference in results. Thus, therapists and therapists in training were retained in the sample and therapist status was not controlled for in any of the analyses.

\section{Research Questions}

Research Question 1: How many clients have concealed and/or disclosed at least one secret in therapy?

Frequencies and percentages of clients who concealed and/or disclosed at least one secret in therapy are displayed in Table 3. Results showed that 47 participants (46\%) had disclosed at least one secret and were concealing at least one secret, 39 participants (39\%) had disclosed at least one secret and were not concealing any secrets, 5 participants (5\%) had not disclosed any secrets and were currently concealing at least one secret, and 10 participants (10\%) had disclosed no secrets and were keeping no secrets from their therapists. Thus, most of the participants (85\%) had revealed at least one 
Table 3

Frequencies and Percentages of Disclosing Versus Concealing Secrets

Disclosed secret

\begin{tabular}{lcccc} 
& & Yes & No & Total \\
\hline Concealed secret & Yes & $47(46.5 \%)$ & $5(5.0 \%)$ & $52(51.5 \%)$ \\
& No & $39(38.6 \%)$ & $10(9.9 \%)$ & $49(48.5 \%)$ \\
& Total & $86(85.1 \%)$ & $15(14.9 \%)$ & \\
\hline
\end{tabular}

secret to their therapists, and about half (52\%) were concealing at least one secret from their therapists at the time of completing the study.

Research Question 2: What types of secrets are concealed versus disclosed?

Table 4 shows the frequencies and percentages of the types of secrets clients concealed versus disclosed. Given that participants were not limited in the number of categories they selected, many listed multiple categories in their responses. The most common types of secret concealed in therapy were sexual secrets, followed by drug or alcohol use. The least common types of secrets concealed were health problem, cheating, lawbreaking, eating habits, and sexual orientation. The most common types of secrets revealed to therapists were relationship difficulties and sexual secrets. The least common secrets revealed to therapists were cheating, sexual orientation, and law breaking. Research Question 3: What are the reasons for concealing versus disclosing secrets?

Table 5 shows the frequencies and percentages regarding the reasons for concealing secrets, and Table 6 shows the frequencies and percentages for disclosing secrets (recall that participants could list more than one reason). The most common reason for concealing a secret was shame/embarrassment, followed by not being motivated to address secret, feeling that other things were more important to talk about, 
Table 4

Types of Secrets Concealed Versus Disclosed

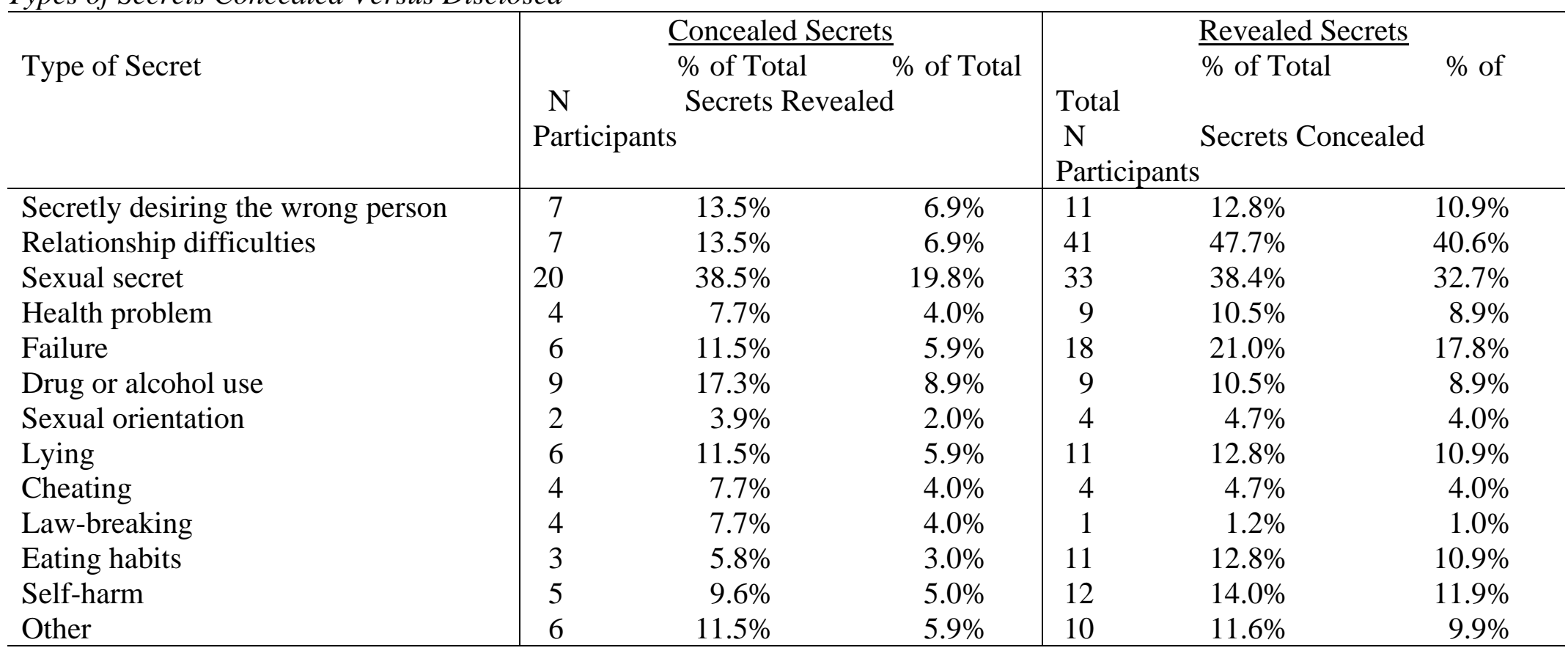


Table 5

Frequencies and Percentages of Reasons for Concealing Secrets

\begin{tabular}{|c|c|c|c|}
\hline Reason for Concealment & $\mathrm{N}$ & $\begin{array}{l}\text { \% of Total } \\
\text { Secrets Concealed }\end{array}$ & $\begin{array}{l}\text { \% of Total } \\
\text { Participants }\end{array}$ \\
\hline I am afraid to express my feelings. & 18 & $34.6 \%$ & $17.8 \%$ \\
\hline $\begin{array}{l}\text { I am too ashamed or embarrassed. } \\
\text { Revealing the secret would show my therapist how }\end{array}$ & 39 & $75.0 \%$ & $38.6 \%$ \\
\hline little progress I have made. & 13 & $25.0 \%$ & $12.9 \%$ \\
\hline There was no time. & 4 & $7.7 \%$ & $4.0 \%$ \\
\hline $\begin{array}{l}\text { I would not tell anyone. } \\
\text { I am not motivated to address the secret. }\end{array}$ & $\begin{array}{r}9 \\
23\end{array}$ & $\begin{array}{l}17.3 \% \\
44.2 \%\end{array}$ & $\begin{array}{r}8.9 \% \\
22.8 \%\end{array}$ \\
\hline $\begin{array}{l}\text { I am being loyal to another person. } \\
\text { Other things are more important to talk about. } \\
\text { Other }\end{array}$ & $\begin{array}{r}2 \\
19 \\
8\end{array}$ & $\begin{array}{r}3.9 \% \\
36.5 \% \\
15.4 \%\end{array}$ & $\begin{array}{r}2.0 \% \\
18.8 \% \\
7.9 \%\end{array}$ \\
\hline
\end{tabular}

Table 6

Frequencies and Percentages of Reasons for Disclosing Secrets

\begin{tabular}{|c|c|c|c|}
\hline Reason for Disclosure & $\mathrm{N}$ & $\begin{array}{l}\text { \% of Total Secrets } \\
\text { Revealed }\end{array}$ & $\begin{array}{l}\% \text { of Total } \\
\text { Participants }\end{array}$ \\
\hline I trust my therapist. & 71 & $82.6 \%$ & $70.3 \%$ \\
\hline $\begin{array}{l}\text { My therapist responded positively to a smaller } \\
\text { secret. }\end{array}$ & 27 & $31.4 \%$ & $26.7 \%$ \\
\hline $\begin{array}{l}\text { I told someone else about the secret first, which } \\
\text { prompted me to tell my therapist. }\end{array}$ & 9 & $10.5 \%$ & $8.9 \%$ \\
\hline $\begin{array}{l}\text { Keeping the secret became too burdensome. } \\
\text { I felt like keeping the secret was preventing me }\end{array}$ & 22 & $25.6 \%$ & $21.8 \%$ \\
\hline from making progress in therapy. & 56 & $65.1 \%$ & $55.5 \%$ \\
\hline My therapist asked me directly about it. & 11 & $12.8 \%$ & $10.9 \%$ \\
\hline I thought I would benefit from sharing the secret. & 65 & $75.6 \%$ & $64.4 \%$ \\
\hline I want my therapist to know the real me. & 51 & $59.3 \%$ & $50.5 \%$ \\
\hline
\end{tabular}


and being afraid to express feelings. Least commonly selected reasons were loyalty to another and lack of time. The most common reasons for disclosing secrets were trusting the therapist, thinking that s/he could benefit from sharing the secret, and feeling like keeping the secret prevented the participant from making progress in therapy. Least commonly selected were the therapist asking directly about the secret and telling someone else about the secret first, which prompted him/her to tell the therapist.

Research Question 4: How do the gains clients imagine they would get by sharing their undisclosed secrets with their therapists compare to the gains they actually received by revealing secrets to their therapists?

Table 7 lists the frequencies and percentages of imagined gains and experienced gains. For both experienced gains and imagined gains, the most common responses were getting feedback- insight, getting emotions out- relief, and giving the therapist information s/he needs. The least common reported gain was “nothing.”

Research Question 5: What do clients believe might influence them to disclose their currently undisclosed secrets?

Table 8 lists the frequencies and percentages of factors participants believe might influence them to disclose their currently concealed secrets. The most commonly reported factors were if keeping the secret prevented the participant from making progress in therapy, if the therapist asked more directly about it, and if keeping the secret became too burdensome. The least common responses were if the therapist responded positively to a smaller secret, if the participant had told someone else about the secret first, and that the participant would not share the secret under any circumstances. 
Table 7

Frequencies and Percentages of Imagined Gains Versus Actual Gains

\begin{tabular}{|c|c|c|c|c|c|c|}
\hline \multirow[b]{2}{*}{ Gains } & \multicolumn{3}{|c|}{ Concealed Secrets (Imagined Gains) } & \multicolumn{3}{|c|}{ Disclosed Secrets (Actual Gains) } \\
\hline & $\mathrm{N}$ & $\begin{array}{l}\% \text { of Total } \\
\text { Secrets Revealed }\end{array}$ & $\begin{array}{l}\% \text { of Total } \\
\text { Participants }\end{array}$ & $\mathrm{N}$ & $\begin{array}{l}\% \text { of Total } \\
\text { Secrets Concealed }\end{array}$ & $\begin{array}{l}\% \text { of Total } \\
\text { Secrets }\end{array}$ \\
\hline Get more feedback- insight & 30 & $57.7 \%$ & $29.7 \%$ & 66 & $76.7 \%$ & $65.4 \%$ \\
\hline Get emotions out- relief & 28 & $53.9 \%$ & $27.7 \%$ & 65 & $75.6 \%$ & $64.4 \%$ \\
\hline Found a solution & 15 & $28.9 \%$ & $14.9 \%$ & 15 & $17.4 \%$ & $14.9 \%$ \\
\hline Gave the therapist information s/he needs & 27 & $51.9 \%$ & $26.7 \%$ & 53 & $61.6 \%$ & $52.5 \%$ \\
\hline Other & 2 & $3.9 \%$ & $2.0 \%$ & 2 & $2.3 \%$ & $2.0 \%$ \\
\hline Nothing & 11 & $21.2 \%$ & $10.9 \%$ & 2 & $2.3 \%$ & $2.0 \%$ \\
\hline
\end{tabular}

Table 8

Frequencies and Percentages for Potential Influences of Disclosure

\begin{tabular}{|c|c|c|c|}
\hline Influences & $\mathrm{N}$ & $\begin{array}{l}\text { \% of Total } \\
\text { Secrets Concealed }\end{array}$ & $\%$ of Total Participants \\
\hline $\begin{array}{l}\text { If I trusted my therapist more/had a better } \\
\text { relationship with my therapist. }\end{array}$ & 9 & $17.3 \%$ & $8.9 \%$ \\
\hline $\begin{array}{l}\text { If I had more sessions with my therapist. } \\
\text { If my therapist responded positively to a }\end{array}$ & 13 & $25.0 \%$ & $12.9 \%$ \\
\hline smaller secret. & 4 & $7.7 \%$ & $4.0 \%$ \\
\hline If I told someone else about the secret first. & 4 & $7.7 \%$ & $4.0 \%$ \\
\hline $\begin{array}{l}\text { If keeping the secret became too burdensome. } \\
\text { If I felt like keeping the secret was preventing }\end{array}$ & 31 & $59.6 \%$ & $30.7 \%$ \\
\hline me from making progress in therapy. & 37 & $71.2 \%$ & $36.6 \%$ \\
\hline $\begin{array}{l}\text { If my therapist asked me more directly about it. } \\
\text { Under no circumstances would I share my }\end{array}$ & 33 & $63.5 \%$ & $32.7 \%$ \\
\hline secret with my therapist. & 3 & $5.8 \%$ & $3.0 \%$ \\
\hline Other & 2 & $3.9 \%$ & $2.0 \%$ \\
\hline
\end{tabular}


Research Question 6: On average, do clients differ in the extent to which they feel positive versus negative emotions when they think about their experience immediately after having disclosed a secret versus when they think about the secrets they are concealing?

Figure 1 shows the means and standard errors for positive and negative emotions related to concealment and disclosure. I conducted a paired samples t-test to compare the level of negative emotion felt regarding concealing a secret to the level of negative emotion felt regarding having just disclosed a secret. For this analysis, only those participants who reported having revealed at least one secret and who were concealing at least one secret were included $(\mathrm{N}=47)$. The paired-samples t-test indicated that participants experienced significantly more negative emotion when they thought about having just revealed a secret to their therapist $(M=4.13, S D=1.19)$ than when they thought about concealing their secret from their therapist $(M=3.71, S D=1.24), t(46)=$ 2.06, $p<.05, d=.35$.

I then conducted a paired samples t-test to compare the level of positive emotion felt regarding concealing a secret to the level of positive emotion felt regarding having just disclosed a secret. Again, for this analysis, only those participants who reported having revealed at least one secret and who were concealing at least one secret were included $(\mathrm{N}=47)$. The paired-samples t-test indicated that participants felt significantly more positive emotion when they thought about having just disclosed their secret to their therapist $(M=3.82, S D=1.05)$ versus when they thought about concealing their current secret from their therapist $(M=2.31, S D=.89), t(47)=7.48, p=.00, d=1.55$. Thus, both negative and positive emotions were rated as higher when clients thought about 
having just disclosed a secret versus when they thought about concealing a secret.

Research Question 7: On average, do clients differ in the extent to which they feel positive versus negative emotions when they think about their experience immediately after having disclosed a secret versus when they reflect on their current feelings about the secret they disclosed earlier?

Table 9 shows the means and standard deviations of the levels of positive and negative emotions reported by the sample in this study, with comparison data from other studies where available. Previous studies have only reported emotions experienced immediately following a self-disclosure in therapy. Figure 1 shows the means and standard errors of positive and negative emotions related to initial disclosure and current feelings about the disclosure. I conducted a paired samples t-test to compare the level of negative emotions felt having just disclosed a secret versus the level of negative emotions felt currently about having disclosed the secret (although remember that both ratings were completed at the same time). For this analysis, only those participants who had revealed at least one secret to their therapist were included $(\mathrm{N}=86)$. Results showed that participants felt significantly more negative emotion immediately after having disclosed their secret to their therapist versus currently, $M=3.87, S D=1.38$ vs. $M=2.35, S D=1.20, t(85)=13.64, p=.00, d=$ 1.18. I next conducted a paired samples t-test to compare the level of positive emotions felt having just disclosed a secret versus the level of negative emotions felt currently about having revealed the secret. Again, for this analysis, only those participants who had revealed at least one secret to their therapist were included $(\mathrm{N}=86)$. Results indicated that participants felt significantly less positive emotion immediately after 
Table 9

Means and Standard Deviations of Level of Positive and Negative Emotions as

Compared to Norm Data

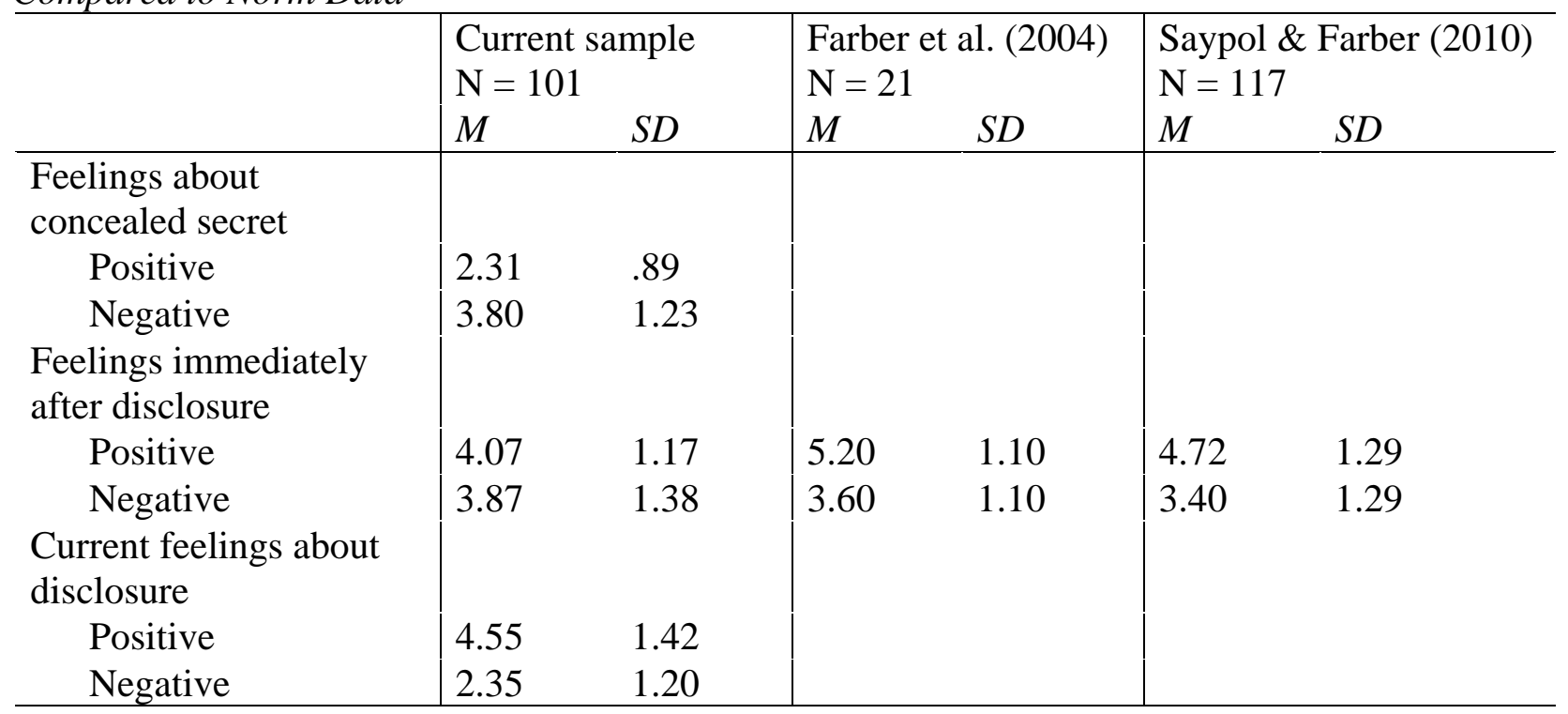

having disclosed their secret to their therapist versus currently, $M=4.07, S D=1.17$ vs. $M$ $=4.55, S D=1.42, t(51)=-4.73, p=.00, d=.37$.

Thus, negative emotions were higher and positive emotions were lower when clients thought about having just disclosed their secret versus when they thought about their current feelings regarding the disclosure.

Research Question 8: Is there a difference in the relationship between concealment and working alliance bond versus disclosure and working alliance bond?

The point biserial correlation between working alliance bond and whether or not a secret was being concealed in therapy was $-.07, p>.05$. The point biserial correlation between working alliance bond and whether or not a secret had been revealed in therapy was .07, $p>.05$. Note that length of therapy was not controlled for given that it was not significantly related to the working alliance, disclosure, or concealment. Neither 
correlation was significant, indicating that working alliance bond was not related to whether or not secrets were revealed or concealed. Furthermore, a z-test used to calculate the difference between these two dependent correlations was not significant, $z=.98 p$ $>.05$, indicating no difference between the relationship for concealed versus revealed secrets and working alliance bond.

Additionally, I performed a simultaneous regression to determine whether disclosure and concealment contribute uniquely to variance in the working alliance bond. The regression equation was not significant, $(F(1,99)=.62, p>.05)$, indicating that neither disclosure nor concealment were predictors of working alliance bond.

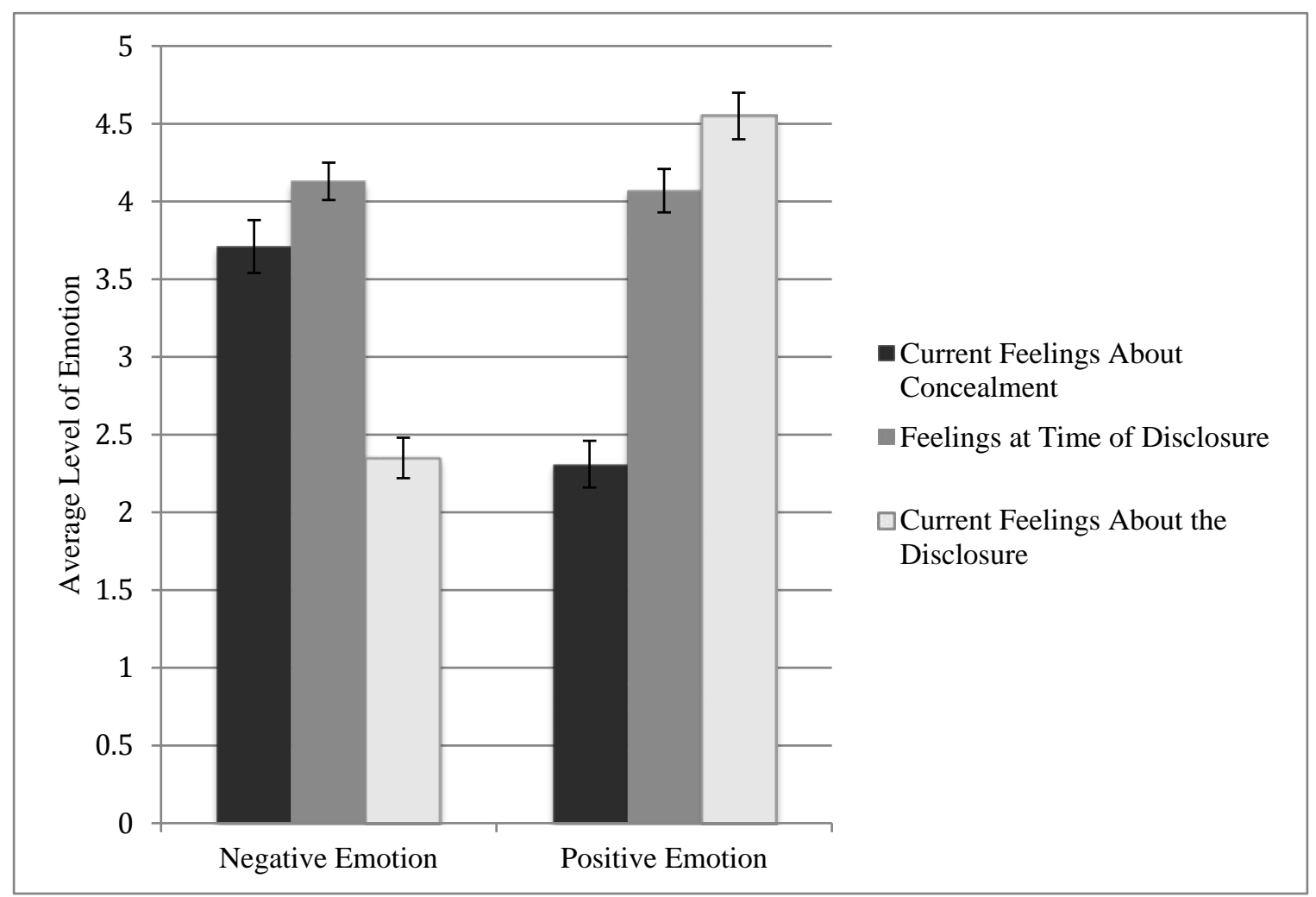

Figure 1. Negative and Positive Emotions Regarding Concealment, Feelings Immediately Following Disclosure, Feelings at Time of Survey Regarding Disclosure 
Research Question 9: Is there a difference in the relationship between concealment and the real relationship versus disclosure and the real relationship?

The partial point biserial correlation between the real relationship and whether or not a secret was being concealed in therapy, controlling for the number of sessions given the positive relationship with the real relationship ( $r=.24, p<.05)$, was $-.28, p<.01$. The partial point biserial correlation between the ratings of the real relationship and whether or not a secret had been disclosed in therapy, again controlling for the number of sessions, was .12, $p>.05$. Thus, although there was no relationship between the real relationship and whether or not secrets were disclosed, there was a significant relationship between the real relationship and whether not secrets were concealed. Those who were concealing at least one secret were more likely to report a weaker real relationship than those who were not concealing a secret. Furthermore, the z-test used to calculate the difference between these two dependent correlations was significant, $z=$ 2.98, $p<.01$, indicating that concealment was more related to the real relationship than was disclosing.

Additionally, I performed a simultaneous regression to determine whether disclosure and concealment contribute uniquely to variance in the real relationship. I included number of sessions, disclosure, and concealment as predictor variables. The variables collectively accounted for $12.4 \%$ of the variance. Concealment accounted for $8.0 \%$ of the variance $(\beta=-.29, p<.01)$, while disclosure was not a significant predictor $(\beta=.15, p>.05)$ 
Research Question 10: Is there a difference in the relationship between concealment and treatment progress versus disclosure and treatment outcome?

The partial point biserial correlation between the COM (a measure of changes since starting therapy) and whether or not a secret had been disclosed in therapy, controlling for number of sessions since it was correlated with the COM $(r=.28, p=$ $.01)$, was .10, $\mathrm{p}>.05$. The partial point biserial correlation between the COM and whether or not a secret was being concealed in therapy, controlling for number of sessions, was -.08, $p>$.05. Thus, neither correlation was significant. Furthermore, a ztest used to calculate the difference between these two dependent correlations was not significant, $z=1.37, p>.05$. Hence, it appears that revealing and concealing secrets were not related to perceived changes since starting therapy.

The point biserial correlations between the ORS (post-only measure of functioning over the past week) and whether or not a secret had been revealed, not controlling for number of sessions since it was not significantly related to ORS, was .04, $p>.05$. The partial point biserial correlation between the COM and whether or not a secret was being concealed in therapy was $-.06, p>.05$. Thus, neither correlation was significant. Furthermore, the difference between these two dependent correlations, as calculated with a z-test, was not significant, $z=.76, p>.05$. Hence, level of functioning over the past week did not seem to be related to revealing or concealing secrets.

Additionally, I performed a simultaneous regression to determine whether disclosure and concealment contribute uniquely to variance in treatment progress. For this analysis, I combined the ORS and the COM into one treatment progress variable by standardizing the scores by converting them to t-scores and averaging the scores of the 
two variables. The regression equation was not significant, $(F(1,99)=.82, p>.05)$, indicating that neither disclosure nor concealment were predictors of treatment progress.

\section{Additional Analyses}

Participants who indicated that they were concealing a secret at the time of completing the measures were asked whether they thought they would ever reveal their secret to their therapist. Of the 52 participants who said they were concealing a secret, 28 (54\%) said they thought they would reveal the secret and 24 (46\%) said they would not.

Additionally, I conducted paired sample t-tests to analyze the differences in the levels of positive versus negative emotions felt when clients thought about concealing their secret, having just disclosed their shared secret, and their current feelings about their disclosure. A paired-samples t-test indicated that participants felt significantly more negative emotion $(M=3.80, S D=1.23)$ than positive emotion $(M=2.31, S D=.87)$ when they thought about their concealed secret, $t(51)=7.12, p=.00, d=1.40$. There was no significant difference between level of positive and negative emotion $(M=4.07, S D=$ 1.17 vs. $M=3.87, S D=1.38$ ) when participants thought about how they felt immediately after disclosing their secret, $t(85)=-.96 p>.05$. Participants felt significantly more positive emotion $(M=4.55, S D=1.42)$ than negative emotion $(M=2.35, S D=1.19)$ when they reported their current feelings about their disclosure, $t(85)=-9.74, p=.00$. Figure 2 shows the means and standard errors of positive and negative emotions related to initial disclosure and current feelings about the disclosure.

I also isolated the sexual secrets in order to look more closely at the characteristics of this particular kind of secret. However, I found no differences when looking specifically at sexual secrets versus when looking at all types of secrets in terms 
of any of my research questions.

Finally, two therapists reported that after completing the questionnaire, their clients came in to their next session with the therapist and told them the secret they had been concealing. Thus, it appears that for some clients, answering questions about their secrets encouraged them to share the secrets in therapy. Since this was not an outcome that was assessed for all clients, it is unclear whether more clients also chose to disclose their secrets after completing the survey.

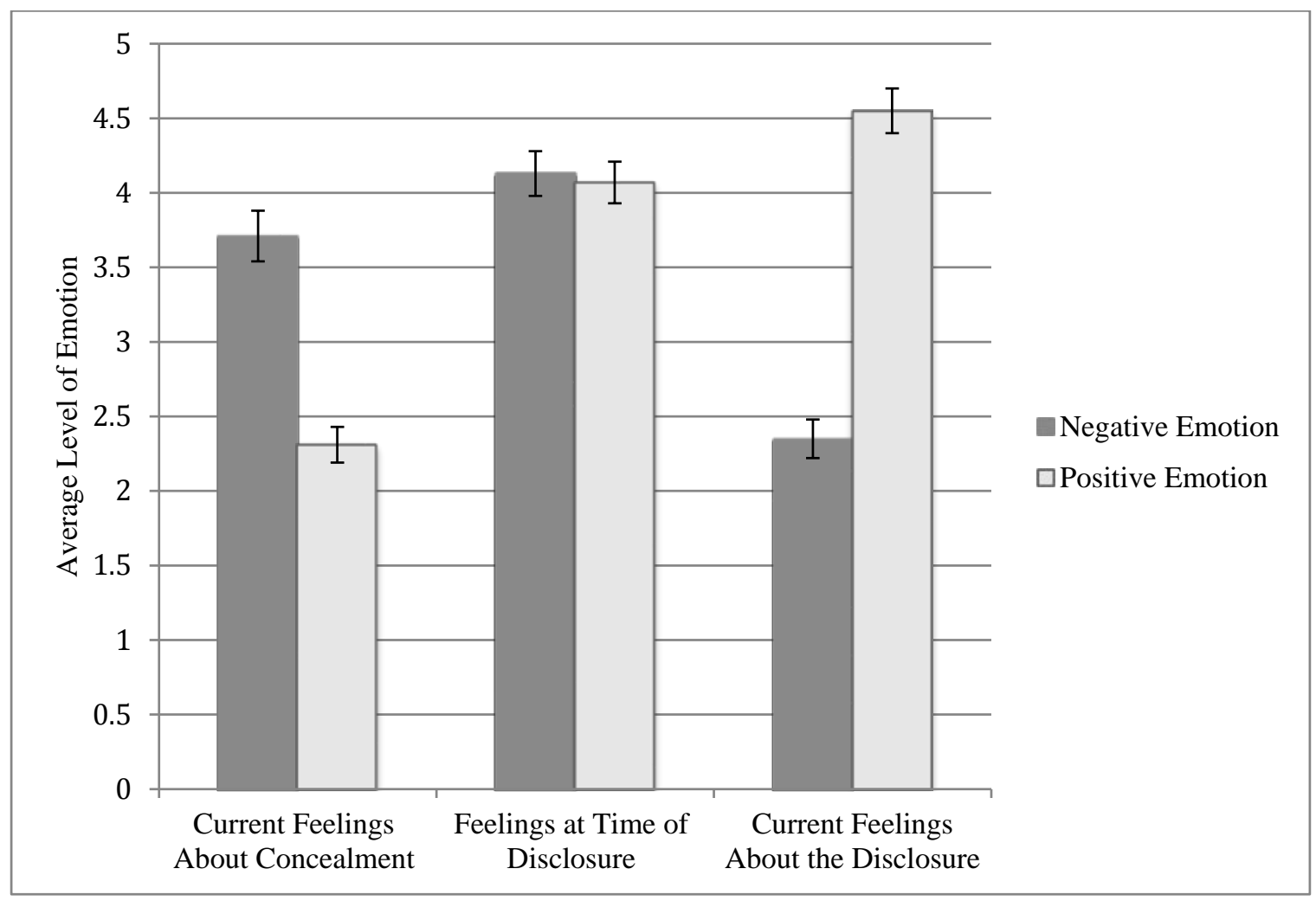

Figure 2. Average Negative and Positive Emotions Regarding Concealment, Feelings Immediately Following Disclosure, and Feelings at Time of Survey Regarding Disclosure 


\section{Chapter 6: Discussion}

In this study, I sought to better understand the client experience of navigating the decision of whether to disclose or conceal a secret in therapy, including their motivations and how they experience the processes of concealment and disclosure.

About half of the participants (52\%) reported that they were concealing a secret from their therapist, a statistic that is similar to those from other studies ( $46 \%$ in Hill et al., 1993; 40\% in Kelly, 1998; 28\% in Kelly \& Yuan, 2009). In addition, 85\% of participants had revealed at least one secret to their therapist. While previous studies have assessed how much clients tend to disclose on a variety of topics or when distressed (Farber \& Hall, 2002; Kahn \& Hessling, 2001), this is the first study to assess actual instances of client disclosures of secrets. This finding suggests that most clients disclose personal material in therapy that they conceal from others in their lives. In addition, $46 \%$ of participants reported that they had both revealed secrets to their therapists and were actively concealing at least one secret from their therapists, indicating that concealment and disclosure do indeed occur simultaneously in therapy. This finding supports the idea that deciding whether to conceal or disclose a secret is a complex and sometimes difficult process and that clients have trouble revealing all of their secrets with their therapists, even if they have disclosed secrets previously (Farber et al., 2004).

Finally, $10 \%$ of clients reported that they had no secrets to either disclose or conceal. It may be that these clients consider themselves an open book, keeping secrets from no one. Alternatively, it could be that these clients were less self-aware and less able to identify secrets that they may hold. They may be invested in not acknowledging their secrets in an effort to avoid distress. 


\section{Characteristics of Concealment in Therapy}

As in previous studies (Hill et al., 1993; Kelly \& Yuan, 2009), concealment was not related to time in therapy, indicating that clients were not less likely to conceal a secret the longer they were in therapy. One reason that time might not have been related to concealment pertains to how concealment was measured. Clients were asked whether or not they were keeping at least one secret in therapy. Thus, clients who were keeping multiple secrets would continue to endorse this question, even if over time, they did share some of these secrets with their therapist. Perhaps this method of assessing is not specific enough to assess how concealment changes over time. On the other hand, only $25 \%$ of participants who were keeping a secret indicated that having more sessions with their therapist (i.e. more time) might lead them to disclose their secret. Thus, perhaps for many clients, other variables matter more than time. The majority of the clients reported that they would share their secret if it prevented them from making progress in therapy. However, perhaps the impasse in therapy caused by the secret happens at different times for different clients or does not happen at all, meaning that clients may continue keeping secrets regardless of their time in therapy. If they can benefit from therapy without revealing their secrets, it makes sense that they would not want to disclose and risk possible shame.

Interestingly, gender seemed to make a difference, in that men were more likely to conceal a secret than were women in this study. Findings have been mixed in terms of whether or not there are gender differences related to concealment, with some studies finding no gender differences (Kelly \& Achter, 1995; Kelly \& Yuan, 2009; Larson \& Chastain, 1990) and others finding that men tend to conceal more and disclose their 
distress less than do women (Cramer \& Barry, 1999; Kahn \& Hessling, 2001). One reason for the inconsistent findings could be that the samples have tended to be comprised primarily of women, (e.g. $76 \%$ of participants in this study). As is the case with small sample sizes, having a low number of male participants means there is an increased risk of the sample being nonrepresentative simply by chance. Therefore, it is unclear whether the finding in my study represents an anomaly of the sample or a true gender difference.

The most common type of concealed secret was a sexual secret, with over a third of clients indicating that their concealed secrets were of this type. Similarly, although Kelly (1998) found that the most common type of secrets were desire/relationship difficulties, most other studies (Hill et al., 1993; Kelly \& Yuan, 2009; Norton et al., 1974; Vrij et al., 2002; Yalom, 1970) have found that secrets in therapy (and in fact, secrets in general) tend to be sexual in nature. A common theory for this is that the subject of sex may be considered taboo in our culture, which might make it feel more risky to disclose (Norton et al., 1974). Additionally, Hill et al. (1993) theorized that some therapists might experience discomfort in talking about sex and thus veer away from it in therapy, which may give clients subtle cues that it is not acceptable to discuss sex.

The most common reason (75\%) for concealing a secret in therapy was shame or embarrassment, which is similar to results found in other studies for concealing secrets both in and outside of therapy (Hill et al., 1993; Kelly \& Yuan, 2009; Seibold, 2008; Vrij et al., 2002). The second-highest endorsed reason (44\%) was a lack of motivation to address the secret, which is more than the 13 percent reported by Kelly and Yuan (2009). One possible reason for this discrepancy is that participants in this current study were 
permitted to select multiple reasons for not sharing their secret whereas Kelly and Yuan (2009) restricted participants to selecting just one reason. Perhaps allowing clients to select multiple reasons for concealing their secrets gives a slightly different picture of their motivations. However, it remains unclear why these participants are not motivated to share their secret. Given that shame was the most common reason for concealing secrets, it might be that some clients were not motivated to discuss their secrets because they did not wish to confront the shame that they were feeling.

The most common gains that participants imagined they might receive, were they to share their secrets, were insight, relief, and giving the therapist important information, with around $50 \%$ of clients who were concealing a secret endorsing each of these gains. Additionally, 20\% of those who were concealing a secret reported that they imagined there would be no gain in sharing their secret. Kelly (1998) found that the most common imagined gains were insight and relief, but also found that giving the therapist information s/he needs and receiving no gains from sharing were among the least common responses (7\% of the sample each). The differences in results may be due to methodological differences. Participants from Kelly (1998) answered an open-ended question about gains, whereas clients in this sample completed a checklist. Perhaps seeing the different available responses in the checklist allowed clients to think through their reasons differently than they would have if they had been asked an open-ended question and had to think of their own reasons.

It seems from the responses that many clients can imagine scenarios where disclosing would yield potential gains. However, the $20 \%$ of secret keepers who reported they would receive no gains from sharing their secrets may represent an important subset 
of clients. Given that many of these same participants also reported that they did not think they would ever share their secret (73\% of those who imagined no gains), it might be that these clients have decided there is no point to revealing their secret and instead choose to bury it with no intention of ever unburdening themselves with it.

When asked about why they might share their secret in therapy, the most common reasons were if the secret were preventing progress (71\%), if the therapist asked directly about it (64\%), or if keeping the secret became too burdensome (60\%). Since this question was created for this study, no comparison data is available from other studies. However, the idea that a secret could become too burdensome and prevent progress in therapy suggests there is a psychic cost involved when actively concealing a secret. This idea fits with inhibition theory, which posits that the energy required to conceal a secret is stressful and may ultimately lead to negative physical and psychological outcomes (e.g. Pennebaker, 1985). This idea also relates to the preoccupation model, which theorizes that concealment may lead to rumination about a secret, which could make it challenging for clients to explore other issues deeply in therapy (Lane \& Wegner, 1985). These findings, however, suggest that clients have some understanding of the potential costs of concealment and that they would consider disclosing their secrets if they became aware of these negative impacts.

Additionally, the finding that many clients would share their secret if the therapist asked them directly about it fits with Balmforth and Elliott's (2012) case study, in which the client disclosed her experience of being abused after she made a general comment about abuse and her therapist asked her if she had ever been abused. Courtois (1988) recommended that therapists ask their clients about more sensitive issues such as 
sexual abuse in order to show that discussion of such topics is acceptable in therapy. Perhaps in some cases, clients need permission and support to feel safe enough to reveal their secrets.

Over half of the participants keeping a secret believed that they would eventually share their secret with their therapist. This finding suggests that there is in fact an inner negotiation process that goes with secret keeping in therapy, and that choosing to conceal a secret is not necessarily a final decision. This fits with findings from one longitudinal study of secrets outside of therapy, which showed that over a 4-month period of time, $29 \%$ of individuals who were keeping a secret had chosen to share their secret with a new confidante (Vrij et al., 2002). However, in this study, it is unclear whether this finding represents a clear intent to share their secret or a hope that it will someday feel tolerable to share.

Finally, participants experienced more negative than positive emotion when thinking about their current feelings about their concealed secrets. This finding fits with the participants' feelings of shame and embarrassment about the concealed secrets. This finding is also consistent with the literature, which associates concealment with negative psychological and physical wellbeing (e.g., Pennebaker, 1985; Vrij et al., 2002).

Taken together, the findings indicate that there are some negative aspects associated with concealment of secrets.

\section{Characteristics of Disclosure in Therapy}

Disclosure was not associated with length of time in therapy. In contrast, previous research has found that disclosure was associated with length of time in therapy (Farber \& Hall, 2002). One potential explanation for the difference in findings relates to 
the difference in the type of disclosure measured in this study. For this study, only disclosure of secrets was assessed, whereas other studies have assessed disclosure on a variety of topics. The findings suggest that, although general disclosure is associated with length of time in therapy, disclosure specific to secrets is not.

In addition, as with other research (Farber \& Hall, 2002; Pattee \& Farber, 2008; Saypol \& Farber, 2010), disclosure was not associated with gender. One previous study found a difference in the types of topics men versus women disclosed (Saypol \& Farber, 2010), but overall disclosure has been similar for men and women (Farber \& Hall, 2002; Pattee \& Faber, 2008; Saypl \& Farber, 2010). The same appears to be true for disclosure of secrets.

The most common types of secrets revealed to therapists were relationship difficulties (48\%) and sexual secrets (38\%). Similarly, previous researchers have found that issues surrounding relationships (e.g. intimacy) were among the most commonly disclosed (Farber \& Hall, 2002; Farber \& Sohn, 2007), but that sexual topics were among the least common disclosures (Farber \& Hall, 2002; Farber \& Sohn, 2007). Differences in the findings may be due in part to differences in defining and assessing disclosures. In previous studies, participants were asked to rate the extent to which they disclosed about certain topics in therapy in general. However, participants in the current study were asked about one specific secret, and this specific secret may have been more salient than general disclosures. In addition, other researchers asked about disclosures related to personal topics, but did not specifically ask about secrets (Farber \& Hall, 2002). Since we know that secrets tend to be sexual in nature, it makes sense that when a client discloses a secret, there is a good chance it would be sexual. 
The most common reasons for choosing to disclose a secret were trusting the therapist (83\%), thinking that s/he could benefit from sharing the secret (76\%), and feeling like keeping the secret prevented the client from making progress in therapy (65\%). Few previous studies have looked at motivation for revealing a secret, but Farber et al. (2004) found that clients believed that keeping secrets inhibited the ability to do therapeutic work, which fits with the finding that some clients felt that concealing their secret prevented them from making progress in therapy. These findings indicate that feeling the effects of keeping the secret, plus feeling like the therapist was trustworthy, encouraged clients to reveal their secret. This fits with Kelly and McKillop’s (1996) recommendation to individuals keeping secrets that they reveal secrets if they are causing them distress and if they have a trustworthy confidante.

Participants commonly reported that they experienced insight gains (77\%) and catharsis (76\%), and that they gave their therapist important information about themselves (62\%) when they shared their secrets. Clients were less likely to report finding a solution as a result of disclosing their secret, indicating that disclosure is more likely to be related to catharsis versus problem solving. Given that secrets tend to be related to shame and embarrassment, perhaps the gains that come from revealing secrets relate more to understanding and releasing the shame surrounding the secret than to finding a solution to a problem. Additionally, only two participants reported no gains from sharing their secrets. Thus, it appears that most clients experienced some positive outcomes from disclosing their secret.

Participants experienced similar levels of negative and positive emotion immediately following their disclosure. Although positive feelings, such as relief and 
authenticity were experienced, comparable levels of negative feelings, such as shame and vulnerability, were also experienced. Unlike the previous findings that clients felt more positive than negative emotion immediately following a disclosure (Farber et al., 2004; Saypol \& Farber, 2010), this finding indicates that disclosing a secret did not bring immediate relief to the secret-keeper. Rather, it suggests that that the process of disclosing a secret is difficult, which fits with previous findings that disclosure was associated with rougher therapy sessions (Stiles, 1984). One reason for the difference in findings may be that in previous studies, participants rated how they typically felt when they made difficult disclosures in therapy, whereas in this study, they rated their feelings related to one specific disclosure. It may be that clients vary in their feelings depending on the disclosure and so when they thought about their general tendencies, they remembered some positive feelings associated with some disclosures. It also may be that participants were better able to remember their mixed feelings when thinking about one specific secret versus when thinking about difficult disclosures in general.

However, over time, the memory of the negative feelings seemed to subside, and positive feelings increased. This pattern fits with previous literature, which indicates that disclosure may have negative short-term effects, but positive long-term effects (Pennebaker et al., 1988). There are a number of reasons that clients might report more positive feelings over time. Clients may experience cognitive dissonance. After making a difficult disclosure, they may change their attitudes towards the experience in order to justify making the decision to disclose. Alternatively, the disclosure may facilitate a corrective experience, where revealing the secret in therapy and receiving the therapist's acceptance allows the client to accept him/herself. 
Though the reasons may not be clear, it does seem that clients appreciate the experience after some time has passed. And despite these positive feelings regarding past disclosures, it continues to be difficult to disclose (Farber et al., 2004).

\section{Comparison of Concealed Versus Disclosed Secrets}

A comparison of concealed versus disclosed secrets revealed some similarities between the secrets clients chose to conceal versus those they decided to disclose. Sexual secrets were among the most commonly concealed and disclosed secrets. Secrets related to lying, cheating, sexual orientation, and health problems were relatively uncommon (Each was selected by fewer than $10 \%$ of the participants). However, disclosed secrets were most likely to be related to relationship difficulties, which was less common for concealed secrets. Perhaps one reason for this is that relationships are considered acceptable to discuss, not taboo as other topics may be viewed. Another reason could be that relationship difficulties may be ongoing (e.g. I'm having intimacy issues with my partner) which might make them difficult to ignore.

The gains that clients imagined they would receive were they to share their concealed secret (insight, relief, giving the therapist important information) were similar to the actual gains reported after disclosing secrets. Since most clients had already disclosed at least one secret, it may be that they anticipated the same gains they had already experienced with disclosing the first secret if they chose to share their concealed secret. However, even though many of them have experienced gains from previous disclosures, something still holds them back.

Additionally, some of the findings related to both concealing and disclosing suggest that clients are engaged in an emotional struggle of weighing the costs and 
benefits when choosing whether to disclose. Clients may feel torn between a desire to unburden themselves and a fear or confronting their shame or being rejected by their therapist. Many of the clients who disclosed did so because they felt they could benefit from the disclosure and because they felt like keeping the secret was preventing progress. Thus, they recognized the importance of disclosing and made the difficult decision to do so. Many who were concealing a secret thought they might share it if the secret became too burdensome or if they felt like it was preventing progress in therapy. These findings indicate that clients ask themselves certain questions about the impact of keeping the secret (i.e. Will I benefit or not? Is keeping this secret too much to bear?) before choosing whether or not to disclose. If the negative aspects of concealment become too salient (e.g. the secret becomes too burdensome or prevents progress), then the client might actually choose to reveal the secret. However, as long as progress is still being made in therapy and as long as the burden is not too great, clients may choose to continue to conceal certain secrets to avoid confronting the difficult issue.

Finally, clients reported higher levels of both positive and negative emotions at the time of disclosure versus when focused on concealing. Thus, compared to how they feel while concealing, emotion level overall seems to be heightened following a disclosure. Positive emotions, such as relief and authenticity, are higher when disclosing than when concealing a secret, but negative feelings, such as vulnerability, are also higher. Some clients may be hesitant to disclose secrets in part because of the heightened emotion that is associated with disclosure. While concealing may allow clients to block some of their shame, disclosing actually brings it to the surface. 


\section{Concealment and Disclosure in Relation to Therapy Process and Outcome}

When there were concealed secrets, the strength of the real relationship was rated as weaker. The findings indicate either that clients hold back certain secrets from their therapists when the strength of the real relationship is low or that when the strength of the real relationship is low, clients choose not to disclose certain secrets to their therapists. A weak real relationship suggests a therapeutic environment where the client does not feel genuinely seen and understood, so it makes sense that this is an environment where secrets are concealed. In contrast, disclosure was not related to the real relationship. Thus, it was more the active process of concealing rather than the catharsis of revealing that mattered.

Neither secret concealment nor secret disclosure was a significant predictor of the working alliance bond. In contrast, previous researchers (Farber \& Hall, 2002; Kelly \& Yuan, 2009) have found a significant positive association between working alliance and disclosure and a significant negative association between working alliance and concealment. One potential reason for the discrepancy in findings may be that in this study, I looked specifically at the working alliance bond instead of looking at all three subscales: goals, task, and bond. Additionally, previous researchers examined overall level of disclosure rather than specifically investigating the disclosure of secrets.

Neither secret concealment nor secret disclosure was related to treatment progress. Previous literature on secrets in therapy has been mixed, with one study showing a positive relationship between secret keeping and treatment outcome and another study showing no relationship between secret keeping and treatment outcome (Kelly, 1998; Kelly \& Yuan, 2009). However, Kelly (1998) controlled for self- 
concealment (one's tendency to conceal) in order to find a positive relationship between secret keeping and outcome, so methodological differences may explain some of the mixed findings. Previous researchers also found that overall disclosure was related to treatment outcome (Farber \& Sohn, 2007). However, this current study looked specifically at disclosure of secrets, which may have different predictive ability than looking at overall disclosure. Additionally, in the current study, treatment progress was assessed through asking clients to compare their current functioning to their level of functioning at the beginning of therapy. It may be that clients have difficulty assessing how they have changed since starting therapy. Perhaps a better way to assess treatment progress is by assessing initial symptomatology and comparing it to current symptomatology. Alternatively, perhaps neither secret keeping nor secret disclosure is correlated with treatment progress. Perhaps clients can improve in therapy whether or not they have disclosed or are concealing secrets.

\section{Limitations}

There are several limitations of the study. One limitation is the low response rate of participants. Only 3\% of therapists contacted responded to my participation request either to agree or to decline to participate. When contacting therapists, I was not directly contacting clients, my selected population, but rather relying on therapists to give the flyer on my study to one of their clients. Thus, it is unclear how many clients were even contacted by their therapists. A number of therapists expressed concern about the sensitive nature of the topic, which may indicate that many chose not to pass along the invitation to their clients. Since I am uncertain how many clients were contacted by their therapists, the actual response rate is difficult to assess. In addition, I tried to control for 
bias by asking therapists to pass the invitation along to the next client who met the criteria, but therapists may have selected clients with whom they felt comfortable or whom they thought would complete the study. So, the generalizability to all clients cannot be made.

Additionally, with the other recruitment methods (listservs, contacting graduate programs, snowball method), it was not possible to calculate a response rate, due to not being certain how many individuals who fit my criteria were reached. Once clients received the information on the study, they self-selected whether or not to participate. Thus, it is uncertain whether the results of this study would generalize to a larger population of clients.

The unique demographics of the sample may also limit generalizability. Clients tended to be well educated (master's degree or above) and tended to be in long-term psychotherapy. Additionally, $21 \%$ of the sample were therapists or therapists-in-training. Although I accounted for apparent differences between therapists and non-therapists by controlling for therapist status when necessary, therapists have a more in-depth understanding of the therapeutic process, which may have influenced the findings in ways for which I could not account. Furthermore, the majority (55\%) of the sample were recruited from announcements in a listserv on the campus of the University of Maryland. Hence, the sample was concentrated in a specific region of the country, and most of the sample were faculty, staff, and graduate students from the university.

Given all these constraints, it is likely that this sample was more open and motivated than a random sample of clients would be. They may have participated out of curiosity, out of a desire to give back for help they had received, out of a desire to let 
someone know about their pain or negative feelings about therapy, or for unknown reasons. However, it is also important to note that the findings in this study were similar to those addressing secrets in other studies, so it is likely that this sample is similar to those of other studies (Hill et al., 1993; Kelly, 1998; Kelly \& Yuan, 2009; Seibold, 2008)

Additionally, the subscales for the positive emotions had low internal consistency, which indicates that the subscales may not be measuring a unidimensional construct of positive emotion. It was problematic that the scale included only four items, and that these items did not seem to hang together well. Thus, findings related to positive emotions should be interpreted with caution.

Finally, it is unclear whether clients answered honestly when asked questions about secrets. Given that the topic of secrets may have brought up feelings of discomfort, participants may have had difficulty answering the questions fully or truthfully.

Additionally, in this study, clients were asked to respond to questions thinking about one concealed secret and one disclosed secret. Clients may have selected secrets that were less distressing to think about or they may have chosen to think about their most salient secrets. Either way, it is unclear whether the findings would generalize to all the secrets clients hold.

\section{Implications}

The findings from this study indicate that clients often conceal secrets from their therapists. Given that therapists often cannot identify when clients are hiding things from them (Hill et al., 1993; Kelly \& Yuan, 2009), therapists may be unaware when clients are concealing secrets. Additionally, they may also have trouble knowing which disclosures are considered secrets by the client, unless the client specifies that s/he has not shared this 
information with others. However, therapists can be aware that certain subject matters, such as sex and relationships, are more likely to encompass secretive material than others. Therapists may consider asking clients more directly about their experiences related to these subjects, when the timing feels appropriate.

Additionally, this study gives further evidence that clients experience shame associated with their secrets, which may contribute to the difficulty in disclosing (Hill et al., 1993; Seibold, 2008). Kelly (1998) theorized that presenting a positive self-image allows the client to be accepted by the therapist and promotes self-acceptance, thereby reducing the shame. However, I would argue that this form of acceptance does not lead to a reduction in shame and other negative feelings, as indicated by the primarily negative feelings related to concealment. Rather, self-acceptance may come from revealing shameful secrets and being accepted by one's therapist anyway. It is therefore important for therapists to create an environment of acceptance in the therapy room where no topics are off-limit. Part of the process of creating this nurturing environment may be for therapists to address their own biases and manage their countertransferences so that true acceptance of the client is possible, no matter what secrets emerge.

The findings also highlight the importance of the therapeutic relationship. Clients shared in part because they had trust in their therapists, which most likely helped them feel safe enough to share. Additionally, a weak real relationship was associated with actively concealing a secret. Having a personal connection with the therapist may be important in order to facilitate the trust that creates the safe environment where a client feels s/he does not have to keep secrets. 
Additionally, the findings suggest an inner negotiation process where clients weigh the costs and benefits of concealing versus disclosing. Farber et al. (2006) found that clients experienced ambivalence leading up to making a difficult disclosure, so they are likely dealing with conflicting thoughts and feelings when deciding whether to share. Therapists can be aware of this process and even bring it up in therapy when clients express uncertainty about disclosing something. Perhaps being able to discuss the pros and cons of disclosing with the therapist has therapeutic benefits, even if the client is not yet ready to share the secret.

Though concealment is often not a finite decision, clients may differ in the amount of readiness they feel regarding the decision to disclose. The finding that half of the sample thought they will one day share their secret in therapy while half did not may reflect where clients fall on the continuum of wanting to reveal themselves in therapy versus wanting to protect themselves from judgment. Some may believe they will never feel ready to disclose their secret, but others may imagine that on some hypothetical day in the future, the timing will feel right, and they will choose to disclose. However, it is unclear whether the intention to disclose someday remains stable over time or whether it varies depending on other factors. It could be that during the course of treatment, clients change in their beliefs of whether or not they will choose to reveal their secret.

Finally, even though there may be long-term benefits, such as insight and relief, disclosing a secret seems to be difficult and may not be a positive experience in the moment. Therapists can be mindful of how difficult the experience of disclosure is and can help support the client as s/he sorts through those mixed feelings. In particular, 
therapists can be aware that clients may be confronting their feelings of shame regarding the secret.

\section{Future Directions}

Studies on concealment and disclosure in therapy have so far been limited to cross-sectional studies where participants report how they feel about their concealed secret in the moment or reflect back on past disclosures. For instance, in this study, participants thought back to how they felt when they first disclosed their secret and rated their positive and negative emotions. However, it is unclear how accurate this retrospective reporting is. Future studies could follow clients longitudinally in order to track what clients choose to conceal and disclose from session to session. This longitudinal method would allow for a more detailed study of the experiences of concealing and disclosing and allow clients to answer questions about these experiences as they happen, rather than reporting retrospectively. It would also allow researchers to track other process and outcome variables along with concealment and disclosure in order to see how they relate.

Researchers could also focus on other attributes of secrets that may relate to process and outcome. Given that Vrij et al. (2002) found differences in well-being between individuals keeping serious and not-so-serious secrets, perhaps assessing the level of secrecy or distress the client associates with his/her secret is a better predictor of treatment outcome or progress than simply assessing whether someone is concealing or has disclosed a secret.

Finally, the role of the therapist in facilitating disclosures still needs to be explored. Farber et al. (2006) found that clients usually look for and receive reassurance 
after making a difficult disclosure. Future research could focus on how therapists might encourage disclosures, how they choose to respond to difficult disclosures, and challenges to identifying and responding appropriately to secrets. 


\section{Appendix A: Working Alliance-Bond Subscale (WAI)}

Below is a list of statements and questions about experiences people might have with their therapy or therapist. Some items refer directly to your therapist with an underlined space - as you read the sentences, mentally insert the name of your therapist in place of in the text. Think about your experience in therapy, and decide which category best describes your own experience.

IMPORTANT!!! Take time to consider each question. Note that the anchors on the scales are different!

1. I believe likes me.

\begin{tabular}{|c|c|c|c|}
\hline $\begin{array}{c}1 \\
\text { eldom }\end{array}$ & $\begin{array}{c}2 \\
\text { Sometimes }\end{array}$ & $\begin{array}{c}3 \\
\text { Fairly Often }\end{array}$ & $\begin{array}{c}4 \\
\text { Very Often }\end{array}$ \\
\hline 1 & 2 & 3 & 4 \\
\hline$m$ & Sometimes & Fairly Often & Very Often \\
\hline
\end{tabular}

3. I feel that appreciates me. 1 23 Seldom Sometimes Fairly Often Very Often Always

4. I feel __ cares even when I do things that he/she does not approve of. $\begin{array}{lllll}1 & 2 & 3 & 4 & 5\end{array}$ Seldom Sometimes Fairly Often Very Often Always 


\section{Appendix B: Real Relationship Index (RRI)}

On the next several items, please use the scale to evaluate your perceptions of yourself, your therapist, and your relationship with your therapist.

1. My therapist liked the "real me."

$\begin{array}{ccccc}5 & 4 & 3 & 2 & 1 \\ \text { Strongly Agree } & \text { Agree } & \text { Neutral } & \text { Disagree } & \text { Strongly Disagree }\end{array}$

2. I was open and honest with my therapist.

$54 \quad 3$

Strongly Agree Agree Neutral
2

Disagree Strongly Disagree

3. My therapist seemed genuinely connected to me. 5 Strongly Agree
4
Agree
3
Neutral
2
Disagree
1
Strongly Disagree

4. My therapist was holding back his/her genuine self. 5
4
3
2
1

Strongly Agree Agree

Neutral

Disagree

Strongly Disagree

5. I appreciated my therapist's limitations and strengths. 5
4
3
2
1
Strongly Agree Agree
Neutral
Disagree
Strongly Disagree

6. We do not really know each other realistically. 5
4
3
2
1 Strongly Agree Agree
Neutral
Disagree
Strongly Disagree

7. My therapist and I were able to be authentic in our relationship. 5
4
Strongly Agree Agree
3
2
Disagree
1
Neutral
Strongly Disagree

8. My therapist and I expressed a deep and genuine caring for one another. 5 Strongly Agree

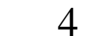
Agree
3 Neutral
2
Disagree
1 Strongly Disagree

2 5 Strongly Agree
4 Agree
3 Neutral
Disagree

2 Disagree

10. My therapist did not see me as I really am.

5

Strongly Agree
4

Agree
3

Neutral
1

Strongly Disagree 
11. I felt there was significant holding back in our relationship.

5

Strongly Agree

12. My therapist's perceptions of me were accurate.

5

Strongly Agree
Agree
3

Neutral
2

Disagree

4

Agree
3

Neutral

3

Coutral

2

Disagree
1 Strongly Disagree

1 Strongly Disagree 


\section{Appendix C: Client Outcome Measure}

Compared to when you started therapy:

1. How do you feel now?

$\begin{array}{ccccccc}1 & 2 & 3 & 4 & 5 & 6 & 7 \\ \text { Much } & \text { Moderately } & \text { Slightly } & \text { About the } & \text { Slightly } & \text { Moderately } & \begin{array}{c}\text { Much } \\ \text { Worse }\end{array} \\ \text { Worse } & \text { Worse } & \text { Same } & \text { Improved } & \text { Improved } & \text { Improved }\end{array}$

2. To what extent has there been a change in your behavior?

$\begin{array}{ccccccc}1 & 2 & 3 & 4 & 5 & 6 & 7 \\ \text { Much } & \text { Moderately } & \text { Slightly } & \text { About the } & \text { Slightly } & \text { Moderately } & \text { Much } \\ \text { Worse } & \text { Worse } & \text { Worse } & \text { Same } & \text { Improved } & \text { Improved } & \text { Improved }\end{array}$

3. To what extent do you seem to understand yourself?

$\begin{array}{ccccccc}1 & 2 & 3 & 4 & 5 & 6 & 7 \\ \text { Much } & \text { Moderately } & \text { Slightly } & \text { About the } & \text { Slightly } & \text { Moderately } & \begin{array}{c}\text { Much } \\ \text { Worse }\end{array} \\ \text { Worse } & \text { Worse } & \text { Same } & \text { Improved } & \text { Improved } & \text { Improved }\end{array}$

4. Rate your overall change in counseling?

\begin{tabular}{|c|c|c|c|c|c|c|}
\hline 1 & 2 & 3 & 4 & 5 & 6 & 7 \\
\hline uc & Moderately & Slightly & About the & Slightly & Moderately & Much \\
\hline I & Worse & Worse & Same & Improved & Improved & Improved \\
\hline
\end{tabular}




\section{Appendix D: Outcome Rating Scale}

Looking back over the last week, including today, help us understand how you have been feeling by rating how well you have been doing in the following areas of your life, where marks to the left represent low levels and marks to the right indicate high levels.

\section{Individually}

(Personal well-being)

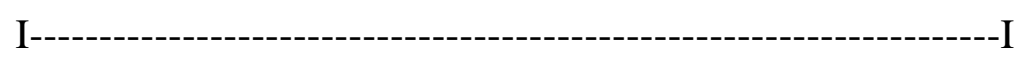

Interpersonally

(Family, close relationships)

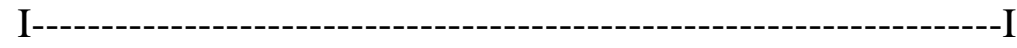

Socially

(Work, school, friendships)

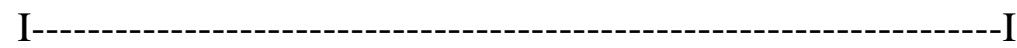

\section{Overall}

(General sense of well-being)

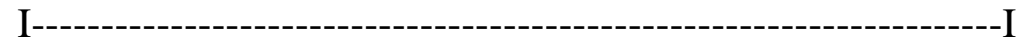




\section{Appendix E: Disclosure and Concealment Questionnaire}

Secrets are defined as life experiences, personal facts, thoughts, or feelings that you intentionally do not disclose.

In therapy, clients often choose to tell some of their secrets to their therapists and to not tell them other secrets. We will be asking you questions about both kinds of secrets today.

Do you have any secrets that you HAVE DISCLOSED to your therapist?

$\square$ Yes

$\square$ No

Please think about ONE secret that you have disclosed to your therapist. Answer the following questions thinking about this ONE secret.

Please select all categories that best describe this secret.

$\square$ Secretly desiring the wrong person

Lying

$\square$ Relationship difficulties

$\square$ Cheating

Sexual secret

Law-breaking

Health problem

Eating habits

Failure

Self-harm

Drug or alcohol use

Other (Please specify:

Sexual orientation 
From the checklist below, please select the reasons that best fit why you decided to share this secret with your therapist. Check all that apply.

I trust my therapist.

My therapist responded positively to a smaller secret.

I told someone else about the secret first, which prompted me to tell my therapist.

Keeping the secret became too burdensome.

I felt like keeping the secret was preventing me from making progress in therapy.

My therapist asked me directly about it.

I thought I would benefit from sharing the secret.

$\square$ I want my therapist to know the real me.

Other (Please specify:

From the checklist below, please select the options that best fit what you think you gained from sharing your secret with your therapist. Check all that apply.

Got more feedback- insight

Get emotions out- relief

Found a solution
Gave the therapist information s/he needs

$\square$ Nothing

$\square$ Other (Please specify: 
Think back to when you disclosed this secret to your therapist. Please rate the extent to which you felt the following emotions immediately after disclosing the secret.

Very little

Somewhat

To a great extent

\begin{tabular}{llllllll} 
Ashamed & 1 & 2 & 3 & 4 & 5 & 6 & 7 \\
\hline Vulnerable & 1 & 2 & 3 & 4 & 5 & 6 & 7 \\
\hline Proud & 1 & 2 & 3 & 4 & 5 & 6 & 7 \\
\hline Exhausted & 1 & 2 & 3 & 4 & 5 & 6 & 7 \\
\hline Sad & 1 & 2 & 3 & 4 & 5 & 6 & 7 \\
\hline Anxious & 1 & 2 & 3 & 4 & 5 & 6 & 7 \\
\hline Authentic, "Real," & 1 & 2 & 3 & 4 & 5 & 6 & 7
\end{tabular}

True to Yourself

\begin{tabular}{llllllll}
\hline Safe & 1 & 2 & 3 & 4 & 5 & 6 & 7 \\
\hline Angry & 1 & 2 & 3 & 4 & 5 & 6 & 7 \\
\hline Relieved & 1 & 2 & 3 & 4 & 5 & 6 & 7 \\
\hline Guilty & 1 & 2 & 3 & 4 & 5 & 6 & 7
\end{tabular}

Now think about your current feelings about this disclosure. Please rate the extent to which you feel the following emotions NOW when you think about having disclosing your secret to your therapist.

Very little

Somewhat

To a great extent

\begin{tabular}{llllllll} 
Ashamed & 1 & 2 & 3 & 4 & 5 & 6 & 7 \\
\hline Vulnerable & 1 & 2 & 3 & 4 & 5 & 6 & 7 \\
\hline Proud & 1 & 2 & 3 & 4 & 5 & 6 & 7 \\
\hline Exhausted & 1 & 2 & 3 & 4 & 5 & 6 & 7 \\
\hline Sad & 1 & 2 & 3 & 4 & 5 & 6 & 7 \\
\hline Anxious & 1 & 2 & 3 & 4 & 5 & 6 & 7 \\
\hline Authentic, "Real," & 1 & 2 & 3 & 4 & 5 & 6 & 7 \\
True to Yourself & & & & & & & 7 \\
\hline Safe & 1 & 2 & 3 & 4 & 5 & 6 & 7 \\
\hline Angry & 1 & 2 & 3 & 4 & 5 & 6 & 7 \\
\hline Relieved & 1 & 2 & 3 & 4 & 5 & 6 & 7 \\
\hline Guilty & 1 & 2 & 3 & 4 & 5 & 6 & 7
\end{tabular}


Research suggests that people tend to keep one or two relevant secrets from their therapists.

Are there any secrets that you HAVE NOT DISCLOSED to your therapist that seem relevant to your therapy?

Yes

No

Please think about ONE secret that you have not disclosed to your therapist. Answer the following questions thinking about this ONE secret.

Please select all categories that best describe this secret.

Secretly desiring the wrong person

Relationship difficulties

Sexual secret

Health problem

Failure

Drug or alcohol use

Sexual orientation $\square$ Lying

Cheating

Law-breaking

Eating habits

Self-harm

Other (Please specify:

From the checklist below, please select the reasons that best fit why you have not shared your secret with your therapist. Check all that apply.

I am afraid to express my feelings.

I am too ashamed or embarrassed.

Revealing the secret would show my therapist how little progress I have made.

There was no time. I would not tell anyone. $\square$ I am not motivated to address the secret.

I am being loyal to another person.

Other things are more important to talk about.

$\square$ Other (Please specify 
From the checklist below, please select the options that best fit what you think you might gain from sharing this secret with your therapist. Check all that apply.

Get more feedback- insight

Get emotions out- relief

Find a solution
Give the therapist information s/he needs

$\square$ Nothing

Other (Please specify:

Under what circumstances might you decide to share this secret with your therapist?

If I trusted my therapist more/had a better relationship with my therapist.

$\square$ If I had more sessions with my therapist.

$\square$ If my therapist responded positively to a smaller secret.

$\square$ If I told someone else about the secret first.

If keeping the secret became too burdensome.

If I felt like keeping the secret was preventing me from making progress in therapy.

$\square$ If my therapist asked me more directly about it.

$\square$ Under no circumstances would I share my secret with my therapist.

$\square$ Other (please specify:

Do you think you will ever share this secret with your therapist?

$\square$ Yes

$\square$ No 
Please rate the extent to which you feel the following emotions when you think about not having shared this secret with your therapist:

Very little Somewhat

To a great extent

\begin{tabular}{|c|c|c|c|c|c|c|c|}
\hline Ashamed & 1 & 2 & 3 & 4 & 5 & 6 & 7 \\
\hline Vulnerable & 1 & 2 & 3 & 4 & 5 & 6 & 7 \\
\hline Proud & 1 & 2 & 3 & 4 & 5 & 6 & 7 \\
\hline Exhausted & 1 & 2 & 3 & 4 & 5 & 6 & 7 \\
\hline Sad & 1 & 2 & 3 & 4 & 5 & 6 & 7 \\
\hline Anxious & 1 & 2 & 3 & 4 & 5 & 6 & 7 \\
\hline $\begin{array}{l}\text { Authentic, "Real," } \\
\text { True to Yourself }\end{array}$ & 1 & 2 & 3 & 4 & 5 & 6 & 7 \\
\hline Safe & 1 & 2 & 3 & 4 & 5 & 6 & 7 \\
\hline Angry & 1 & 2 & 3 & 4 & 5 & 6 & 7 \\
\hline Relieved & 1 & 2 & 3 & 4 & 5 & 6 & 7 \\
\hline Guilty & 1 & 2 & 3 & 4 & 5 & 6 & 7 \\
\hline
\end{tabular}




\section{Appendix F: Demographics Questionnaire}

Gender:

Age:

Race/Ethnicity:

Highest educational degree achieved:

__ High school

__ Some college

__ Bachelor's
Masters

Doctorate

Other

Occupation:

Are you a therapist or a therapist-in-training?

_ Yes No

What issues are you working on in therapy?

About how many sessions have you had with your current therapist?

Theoretical orientation of your therapist:

__ Psychodynamic

Cognitive-Behavioral

Person-centered
Eclectic

Other

Not sure

Gender of therapist:

Race/Ethnicity of therapist: 


\section{Appendix G: Recruitment Email}

Dear [first name],

\section{What do clients disclose and not disclose in therapy? We are doing a survey to investigate this question.}

This project is being conducted by Ellen Baumann and Dr. Clara Hill in the Psychology department at the University of Maryland. The purpose of this research project is to gain understanding of how clients determine what to say versus not say to their therapists. The results of this study may help us learn more about the helpful and hindering processes in therapy and how clients negotiate the sharing process in therapy.

\section{If you yourself are a current client in individual psychotherapy, please consider taking the survey yourself. You may access it at: www.psychotherapystudy.umd.edu}

If you agree to participate in recruiting one of your clients, you may access a handout regarding the study in one of two ways:

1. Download the attached handout

2. Click on the following Qualtrics link to access the handout and print it out: [qualtrics link]

Give the handout to your next client (only give to ONE client) who meets the following requirements:

- $\quad$ Over the age of 18

- In individual psychotherapy

- Has been seen for at least 8 sessions

- Not in crisis

Please hand the flyer to the client and say something like the following:

"I received information about this study today, and I have agreed to pass along the information to the next client I see who is eligible to participate: This happens to be you. I agreed to pass along the information because I believe in supporting psychotherapy research. However, I have no vested interest in this project. It is up to you whether or not you participate, and I will not know what decision you make, nor will I have access to your responses if you do decide to participate. The results of this study may help us better understand the therapy experience from the client perspective. I am not able to answer questions about the study, but if you have questions about participation, please email the researchers at the email listed on the flyer."

If you decide to participate and give this handout to one client, please send me a quick email saying you have done so. If you choose not to participate and would like to opt out of receiving additional reminder emails, please let me know that as well. 
Thank you for your consideration. Please contact us if you have any questions.

Ellen Baumann, B.S., Master’s Student in Counseling Psychology ebaumann@umd.edu

Clara E. Hill, Ph.D., Professor

cehill@umd.edu 


\section{Appendix H: Recruitment Email for Graduate Student Clients}

Subject: Participant recruitment for study on client disclosure

Dear Training Director:

I am requesting your assistance in recruitment for a study on client disclosure, which is being conducted by myself (Ellen Baumann) and Dr. Clara Hill in the Psychology department at the University of Maryland. We are seeking to recruit graduate students who are currently in individual psychotherapy. We would greatly appreciate if you would kindly forward this email to your current students and graduates so that they have the information to participate in our study.

Thank you for your consideration,

Ellen Baumann, BS

Master's Student in Counseling Psychology

Dear Prospective Participants,

My name is Ellen Baumann, and I am a third-year Counseling Psychology doctoral student at the University at Maryland. For my thesis study, I am recruiting graduate students who are also currently clients in individual psychotherapy. The purpose of this research project is to gain understanding of how clients determine what to say versus not say to their therapists.

Please participate in a one-time anonymous survey-It will take 20- 25 minutes. This project is being conducted in the Psychology Department at the University of Maryland. The results of this study may help us learn more about what helps and hinders clients in therapy. In order to participate, you must:

- Be over the age of 18

- Have completed at least 8 sessions of individual therapy with your current therapist

- Still be in therapy with your current therapist

To thank you for participating, you will be given the opportunity to enter a drawing to win one of three \$25 Amazon.com gift cards.

If you are interested in participating, please visit the following secure website:

www.psychotherapystudy.umd.edu

On this website you will find questions about your experience of therapy. Your participation is completely voluntary.

Thank you for your consideration, Ellen Baumann, B.S., Master’s Student in Counseling Psychology ebaumann@umd.edu Clara E. Hill, Ph.D., Professor cehill@umd.edu 


\section{Appendix I: Snowballing Recruitment Email for Clients}

Dear [Name]:

I am requesting your assistance in recruitment for my thesis study on client disclosure, which is being conducted in the Psychology department at the University of Maryland. I am seeking to recruit individuals who are currently in individual psychotherapy. If you are currently in individual psychotherapy, please consider participating in my study. Additionally, I would greatly appreciate if you would kindly forward this email to individuals you believe may be interested in participating so that they have the information to take part in the study.

Thank you for your consideration,

Ellen Baumann, BS

Master's Student in Counseling Psychology

Dear Prospective Participants,

You choose to discuss some things and not other things in therapy. We would like to hear more about that.

Please participate in a one-time anonymous survey - It will take 20- 25 minutes. This project is being conducted in the Psychology Department at the University of Maryland. The results of this study may help us learn more about what helps and hinders clients in therapy.

In order to participate, you must:

- $\quad$ Be over the age of 18

- Have completed at least 8 sessions of individual therapy with your current therapist

- Still be in therapy with your current therapist

To thank you for participating, you will be given the opportunity to enter a drawing to win one of three \$25 Amazon.com gift cards.

If you are interested in participating, please visit the following secure website:

www.psychotherapystudy.umd.edu

On this website you will find questions about your experience of therapy. Your participation is completely voluntary.

Thank you for your consideration,

Ellen Baumann, B.S., Master’s Student in Counseling Psychology

ebaumann@umd.edu

Clara E. Hill, Ph.D., Professor

cehill@umd.edu 


\section{Appendix J: Recruitment Notice for FYI Listserv}

Subject: Are you currently in therapy? Participate in a brief online survey for a chance to WIN \$25!

Are you currently in therapy? Please participate in a one-time anonymous survey regarding what clients choose to say and not say in therapy- It will take 20- 25

minutes. This project is being conducted in the Psychology Department at the University of Maryland. The results of this study may help us learn more about what helps and hinders clients in therapy.

To thank you for participating, you will be given the opportunity to enter a drawing to win one of three $\$ 25$ Amazon.com gift cards.

Website: www.psychotherapystudy.umd.edu

On this website you will find questions about your experience of therapy. Your participation is completely voluntary.

For more information, contact:

Ellen Christina Baumann

ebaumann@umd.edu 


\section{Appendix K: Client Recruitment Flyer \\ You choose to discuss some things and not other things in therapy. We would like to hear more about that.}

Please participate in a one-time anonymous survey-It will take 20- 25 minutes. This project is being conducted in the Psychology Department at the University of Maryland. The results of this study may help us learn more about what helps and hinders clients in therapy.

In order to participate, you must:

- Be over the age of 18

- Have completed at least 8 sessions of individual therapy with your current therapist

- Still be in therapy with your current therapist

To thank you for participating, you will be given the opportunity to enter a drawing to win one of three \$25 Amazon.com gift cards.

If you are interested in participating, please visit the following secure website:

\section{www.psychotherapystudy.umd.edu}

On this website you will find questions about your experience of therapy. Your participation is completely voluntary. Although your therapist has kindly assisted us in recruiting participants, s/he will have no knowledge of whether or not you choose to participate.

Thank you for your consideration,

Ellen Baumann, B.S., Master’s Student in Counseling Psychology

ebaumann@umd.edu

Clara E. Hill, Ph.D., Professor

cehill@umd.edu 


\section{References}

Balmforth, J., \& Elliott, R. (2012). 'I never talked about, ever’: A comprehensive process analysis of a significant client disclosure event in therapy. Counselling \& Psychotherapy Research, 12(1), 2-12. doi:10.1080/14733145.2011.580353

Booth, R. J., Petrie, K. J., \& Pennebaker, J. W. (1997). Changes in circulating lymphocyte numbers following emotional disclosure: Evidence of buffering?. Stress Medicine, 13(1), 23-29. doi:10.1002/(SICI)10991700(199701)13:1<23::AID-SMI714>3.0.CO;2-E

Campbell, A., \& Hemsley, S. (2009). Outcome Rating Scale and Session Rating Scale in psychological practice: Clinical utility of ultra-brief measures. Clinical Psychologist, 13(1), 1-9. doi:10.1080/13284200802676391

Courtois, C. A. (1988). Healing the incest wound. New York: Norton.

Cox, J. B., Brown, T. R., Peterson, P. D.,\&Rowe, M. M. (1982).Areport on a statewide community mental health center outcome study. Community Mental Health Journal, 18, 135-150.

Cramer, K. M., \& Bany, J. E. (1999). Psychometric properties and confirmatory factor analysis of the self-concealment scale. Personality and Individual Differences, 27, 629-637.

Derlega, V. J., Winstead, B. A., Greene, K., Serovich, J., \& Elwood, W. N. (2002). Perceived HIV-related stigma and HIV disclosure to relationship partners after finding out about the seropositive diagnosis. Journal of Health Psychology, 7, 415-432. 
Derogatis, L. R., Abeloff, M. D., \& Melisaratos, N. (1979). Psychological coping mechanisms and survival time in metastatic breast cancer. Journal of the American Medical Association242, 1504-1508.

Farber, B. A., Berano, K. C., \& Capobianco, J. A. (2004). Clients' Perceptions of the Process and Consequences of Self-Disclosure in Psychotherapy. Journal Of Counseling Psychology, 51(3), 340-346. doi:10.1037/0022-0167.51.3.340

Farber, B. A., \& Hall, D. (2002). Disclosure to therapists: What is and is not discussed in psychotherapy. Journal Of Clinical Psychology, 58(4), 359-370. doi:10.1002/jclp.1148

Farber, B. A., Lippert, R. A., \& Nevas, D. B. (1995). The therapist as attachment figure. Psychotherapy: Theory, Research, Practice, Training, 32(2), 204-212. doi:10.1037/0033-3204.32.2.204

Farber, B. A., \& Sohn, A. E. (2007). Patterns of self-disclosure in psychotherapy and marriage. Psychotherapy: Theory, Research, Practice, Training, 44(2), 226-231. doi:10.1037/0033-3204.44.2.226

Finkenauer, C., \& Rimé, B. (1998). Keeping emotional memories secret: Health and subjective well-being when emotions are not shared. Journal Of Health Psychology, 3(1), 47-58. doi:10.1177/135910539800300104

Freud, S. (1913/1958). On beginning the treatment. In J. Strachey (Ed.) The standard edition of the complete psychological works of Sigmund Freud (Vol. 12, pp. 121144). London: Hogarth Press. (Original work published 1913). 
Fuertes, J. N., Mislowack, A., Brown, S., Gur-Arie, S., Wilkinson, S., \& Gelso, C. J. (2007). Correlates of the real relationship in psychotherapy: A study of dyads. Psychotherapy Research, 17(4), 423-430. doi:10.1080/10503300600789189

Fuglestad, P. T., \& Snyder, M. (2010). Status and the motivational foundations of selfmonitoring. Social And Personality Psychology Compass, 4(11), 1031-1041. doi:10.1111/j.1751-9004.2010.00311.x

Gangestad, S. W., \& Snyder, M. (2000). Self-monitoring: Appraisal and reappraisal. Psychological Bulletin, 126(4), 530-555. doi:10.1037/0033-2909.126.4.530

Gelso, C. J., Kivlighan, D. R., Busa-Knepp, J., Spiegel, E. B., Ain, S., Hummel, A. M., \& ... Markin, R. D. (2012). The unfolding of the real relationship and the outcome of brief psychotherapy. Journal Of Counseling Psychology, 59(4), 495-506. doi:10.1037/a0029838

Hall, D. A., \& Farber, B. A. (2001). Patterns of patient disclosure in psychotherapy. Journal Of The American Academy Of Psychoanalysis, 29(2), 213-230. doi:10.1521/jaap.29.2.213.17262

Hatcher, R. L., \& Gillaspy, J. (2006). Development and validation of a revised short version of the Working Alliance Inventory. Psychotherapy Research, 16(1), 1225. doi:10.1080/10503300500352500

Hill, C. E., Gelso, C. J., Chui, H., Spangler, P., Hummel, A., Huang, T., Jackson, J., Jones, R., Palma, B., Bhatia, A., Gupta, S., Ain, S., Klingaman, E., Lim, R. H., Liu, J., Hui, K., Jezzi, M. M., \& Miles, J. R. (2013). To be or not to be immediate with clients: The use and effects of immediacy in psychodynamic/interpersonal 
psychotherapy. Psychotherapy Research, 23, doi:

$10.1080 / 10503307.2013 .812262$

Hill, C. E., Gelso, C. J., \& Mohr, J. J. (2000). Client concealment and self-presentation in therapy: Comment on Kelly (2000). Psychological Bulletin, 126(4), 495-500. doi:10.1037/0033-2909.126.4.495

Hill, C. E., Thompson, B. J., Cogar, M. C., \& Denman, D. W. (1993). Beneath the surface of long-term therapy: Therapist and client report of their own and each other's covert processes. Journal Of Counseling Psychology, 40(3), 278-287. doi:10.1037/0022-0167.40.3.278

Hill, C. E., Thompson, B. J., \& Corbett, M. M. (1992). The impact of therapist ability to perceive displayed and hidden client reactions on immediate outcome in first sessions of brief therapy. Psychotherapy Research, 2(2), 143-155. doi:10.1080/10503309212331332914

Jacobson, N. S., \& Anderson, E. A. (1982). Interpersonal skill and depression in college students: Analysis of the timing of self-disclosures. Behavior Therapy, 13, 271282.

Janse, P., Boezen-Hilberdink, L., van Dijk, M. K., Verbraak, M. M., \& Hutschemaekers, G. M. (2013). Measuring Feedback From Clients: The Psychometric Properties of the Dutch Outcome Rating Scale and Session Rating Scale. European Journal Of Psychological Assessment, doi:10.1027/1015-5759/a000172

Jourard. S.M. (1974). Healthy Personality. An Approach from the Viewpoint of Humanistic Psychology. New York: Macmillan. 
Kahn, J. H., Achter, J. A., \& Shambaugh, E. J. (2001). Client distress disclosure, characteristics at intake, and outcome in brief counseling. Journal Of Counseling Psychology, 48(2), 203-211. doi:10.1037/0022-0167.48.2.203

Kahn, J. H., \& Hessling, R. M. (2001). Measuring the tendency to conceal versus disclose psychological distress. Journal Of Social And Clinical Psychology, 20(1), 41-65. doi:10.1521/jscp.20.1.41.22254

Kazdin, A. E. (2001). Behavior modification in applied settings (6 $6^{\text {th }}$ ed.). Long Grove, IL: Waveland Press

Kelley, F. A., Gelso, C. J., Fuertes, J. N., Marmarosh, C., \& Lanier, S. (2010). The Real Relationship Inventory: Development and psychometric investigation of the client form. Psychotherapy: Theory, Research \& Practice, 47(4), 540-553. doi:10.1037/a0022082

Kelly, A. E. (1998). Clients' secret keeping in outpatient therapy. Journal Of Counseling Psychology, 45(1), 50-57. doi:10.1037/0022-0167.45.1.50

Kelly, A. E. (2000). Helping construct desirable identities: A self-presentational view of psychotherapy. Psychological Bulletin, 126(4), 475-494. doi:10.1037/00332909.126.4.475

Kelly, A. E., \& Achter, J. A. (1995). Self-concealment and attitudes toward counseling in university students. Journal Of Counseling Psychology, 42(1), 40-46. doi:10.1037/0022-0167.42.1.40

Kelly, A. E., \& Kahn, J. H. (1994). Effects of suppression of personal intrusive thoughts. Journal Of Personality And Social Psychology, 66(6), 998-1006. doi:10.1037/0022-3514.66.6.998 
Kelly, A. E., Klusas, J. A., von Weiss, R. T., \& Kenny, C. (2001). What is it about revealing secrets that is beneficial?. Personality And Social Psychology Bulletin, 27(6), 651-665. doi:10.1177/0146167201276002

Kelly, A. E., \& McKillop, K. J. (1996). Consequences of revealing personal secrets. Psychological Bulletin, 120(3), 450-465. doi:10.1037/0033-2909.120.3.450

Kelly, A. E., \& Rodriguez, R. R. (2007). Do therapists self-disclose more to clients with greater symptomatology?. Psychotherapy: Theory, Research, Practice, Training, 44(4), 470-475. doi:10.1037/0033-3204.44.4.470

Kelly, A. E., \& Yip, J. J. (2006). Is Keeping a Secret or Being a Secretive Person Linked to Psychological Symptoms?. Journal Of Personality, 74(5), 1349-1369. doi:10.1111/j.1467-6494.2006.00413.x

Kelly, A. E., \& Yuan, K. (2009). Clients’ secret keeping and the working alliance in adult outpatient therapy. Psychotherapy: Theory, Research, Practice, Training, 46(2), 193-202. doi:10.1037/a0016084

Lane, J. D., \& Wegner, D. M. (1995). The cognitive consequences of secrecy. Journal Of Personality And Social Psychology, 69(2), 237-253. doi:10.1037/00223514.69.2.237

Larsen, D. L., Attkisson, C. C., Hargreaves, W. A., \& Nguyen, T. D. (1979). Assessment of client/patient satisfaction: Development of a general scale. Evaluation and Program Planning, 2(3), 197-207. Retrieved from http://search.proquest.com/docview/74868837?accountid=14696 
Larson, D. G., \& Chastain, R. L. (1990). Self-concealment: Conceptualization, measurement, and health implications. Journal of Social and Clinical Psychology, 9, 439-455.

Major, B., \& Gramzow, R. H. (1999). Abortion as stigma: Cognitive and emotional implications of concealment. Journal Of Personality And Social Psychology, 77(4), 735-745. doi:10.1037/0022-3514.77.4.735

Marmarosh, C. L., Gelso, C. J., Markin, R. D., Majors, R., Mallery, C., \& Choi, J. (2009). The real relationship in psychotherapy: Relationships to adult attachments, working alliance, transference, and therapy outcome. Journal Of Counseling Psychology, 56(3), 337-350. doi:10.1037/a0015169

Martin, D. J., Garske, J. P., \& Davis, M. (2000). Relation of the therapeutic alliance with outcome and other variables: A meta-analytic review. Journal Of Consulting And Clinical Psychology, 68(3), 438-450. doi:10.1037/0022-006X.68.3.438

McDaniel, S. H., Stiles, W. B., \& McGaughey, K. J. (1981). Correlations of male college students' verbal response mode use in psychotherapy with measures of psychological disturbance and psychotherapy outcome. Journal Of Consulting And Clinical Psychology, 49(4), 571-582. doi:10.1037/0022-006X.49.4.571

Norton, R., Feldman, C., \& Tafoya, D. (1974). Risk parameters across types of secrets. Journal Of Counseling Psychology, 21(5), 450-454. doi:10.1037/h0037100

Oyamot, C. M., Fuglestad, P. T., \& Snyder, M. (2010). Balance of power and influence in relationships: The role of self-monitoring. Journal Of Social And Personal Relationships, 27(1), 23-46. doi:10.1177/0265407509347302 
Pattee, D., \& Farber, B. A. (2008). Patients' experiences of self-disclosure in psychotherapy: The effects of gender and gender role identification. Psychotherapy Research, 18(3), 306-315. doi:10.1080/10503300701874534

Pennebaker, J. W. (1985). Traumatic experience and psychosomatic disease: Exploring the roles of behavioural inhibition, obsession, and confiding. Canadian Psychology/Psychologie Canadienne, 26(2), 82-95. doi:10.1037/h0080025

Pennebaker, J. W. (1997). Writing about emotional experiences as a therapeutic process. Psychological Science, 8(3), 162-166. doi:10.1111/j.1467-9280.1997.tb00403.x

Pennebaker, J. W., \& Beall, S. K. (1986). Confronting a traumatic event: Toward an understanding of inhibition and disease. Journal Of Abnormal Psychology, 95(3), 274-281. doi:10.1037/0021-843X.95.3.274

Pennebaker, J. W., \& Chew, C. H. (1985). Behavioral inhibition and electrodermal activity during deception. Journal Of Personality And Social Psychology, 49(5), 1427-1433. doi:10.1037/0022-3514.49.5.1427

Pennebaker, J. W., Kiecolt-Glaser, J. K., \& Glaser, R. (1988). Disclosure of traumas and immune function: Health implications for psychotherapy. Journal Of Consulting And Clinical Psychology, 56(2), 239-245. doi:10.1037/0022-006X.56.2.239

Pennebaker, J. W., \& Susman, J. R. (1988). Disclosure of traumas and psychosomatic processes. Social Science \& Medicine, 26(3), 327-332. doi:10.1016/02779536(88)90397-8

Regan, A. M., \& Hill, C. E. (1992). Investigation of what clients and counselors do not say in brief therapy. Journal Of Counseling Psychology, 39(2), 168-174. doi:10.1037/0022-0167.39.2.168 
Rennie, D. L. (1994). Clients' deference in psychotherapy. Journal Of Counseling Psychology, 41(4), 427-437. doi:10.1037/0022-0167.41.4.427

Roberts, R. E., \& Attkisson, C. (1983). Assessing client satisfaction among Hispanics. Evaluation And Program Planning, 6(3-4), 401-413. doi:10.1016/01497189(83)90019-8

Rogers, C. R. (1957). The necessary and sufficient conditions of therapeutic personality change. Journal Of Consulting Psychology, 21(2), 95-103. doi:10.1037/h0045357

Rippere, V (1977). "What's the thing to do when you're feeling depressed?"—A pilot study. Behaviour Research and Therapy, 15,185-191.

Rosenberg, H. J., Rosenberg, S. D., Ernstoff, M. S., Wolford, G. L., Amdur, R. J., Elshamy, M. R., \& ... Pennebaker, J. W. (2002). Expressive disclosure and health outcomes in a prostate cancer population. International Journal Of Psychiatry In Medicine, 32(1), 37-53. doi:10.2190/AGPF-VB1G-U82E-AE8C

Saypol, E., \& Farber, B. A. (2010). Attachment style and patient disclosure in psychotherapy. Psychotherapy Research, 20(4), 462-471. doi:10.1080/10503301003796821

Seibold, C. (2008). Shame, the affective side of secrets: Commentary on Barth's hidden eating disorders. Clinical Social Work Journal, 36(4), 367-371. doi:10.1007/s10615-008-0168-y

Skinner, B. F. (1938). The Behavior of Organisms: An Experimental Analysis. Cambridge, Massachusetts: B.F. Skinner Foundation. 
Smart, L., \& Wegner, D. M. (1999). Covering up what can't be seen: Concealable stigma and mental control. Journal Of Personality And Social Psychology, 77(3), 474486. doi:10.1037/0022-3514.77.3.474

Snyder, M. ( 1974). Self-monitoring of expressive behavior. Journal of Personality and Social Psychology, 30, 526- 537.

Stiles, W. B. (1987). 'I have to talk to somebody': A fever model of disclosure. In V. J. Derlega, J. H. Berg (Eds.), Self-disclosure: Theory, research, and therapy (pp. 257-282). New York, NY US: Plenum Press. Stiles, 1995

Stiles, W. B., Shuster, P. L., \& Harrigan, J. A. (1992). Disclosure and anxiety: A test of the fever model. Journal Of Personality And Social Psychology, 63(6), 980-988. doi:10.1037/0022-3514.63.6.980

Tabachnick, B. G., \& Fidell, L. (1996). Using multivariate statistics (3 ${ }^{\text {rd }}$ ed.). New York: HarperCollins.

Thompson, B. J., \& Hill, C. E. (1991). Therapist perceptions of client reactions. Journal Of Counseling \& Development, 69(3), 261-265. doi:10.1002/j.15566676.1991.tb01500.x

Uysal, A., Lin, H., \& Knee, C. (2010). The role of need satisfaction in self-concealment and well-being. Personality And Social Psychology Bulletin, 36(2), 187-199. doi:10.1177/0146167209354518

Uysal, A., \& Lu, Q. (2011). Is self-concealment associated with acute and chronic pain?. Health Psychology, 30(5), 606-614. doi:10.1037/a0024287

Vrij, A., Nunkoosing, K., Paterson, B., Oosterwegel, A., \& Soukara, S. (2002). Characteristics of secrets and the frequency, reasons and effects of secrets keeping 
and disclosure. Journal Of Community \& Applied Social Psychology, 12(1), 56-

70. doi:10.1002/casp.652

Wegner, D. M., \& Erber, R. (1992). The hyperaccessibility of suppressed thoughts.

Journal Of Personality And Social Psychology, 63(6), 903-912.

doi:10.1037/0022-3514.63.6.903

Wegner, D. M., Schneider, D. J., Carter, S. R., \& White, T. L. (1987). Paradoxical effects of thought suppression. Journal Of Personality And Social Psychology, 53(1), 513. doi:10.1037/0022-3514.53.1.5

Yalom, I. (1970). The theory and practice of group psychotherapy. New York: Basic Books 